\title{
Recent Advances in Nanotechnology-Aided Materials in Combating Microbial Resistance and Functioning as Antibiotics Substitutes
}

This article was published in the following Dove Press journal: International Journal of Nanomedicine

\author{
Muhammad Usman Munir (iD) 1,2 \\ Arsalan Ahmed ${ }^{3}$ \\ Muhammad Usman ${ }^{4}$ \\ Sajal Salman ${ }^{5}$ \\ 'Department of Pharmaceutical \\ Chemistry, College of Pharmacy, Jouf \\ University, Sakaka, Aljouf 72388, Saudi \\ Arabia; ${ }^{2}$ Nanobiotech Group, Industrial \\ Biotechnology Division, National \\ Institute for Biotechnology and Genetic \\ Engineering (NIBGE), Faisalabad, \\ Pakistan; ${ }^{3}$ Interdisciplinary Research \\ Centre in Biomedical Materials, \\ COMSATS Institute of Information \\ Technology, Lahore 54000, Pakistan; \\ ${ }^{4}$ Department of Physics, Khawaja Fareed \\ University of Engineering and Information \\ Technology, Rahim Yar Khan 64200, \\ Pakistan; ${ }^{5}$ Faculty of Pharmacy, University \\ of Central Punjab, Lahore 54000, Pakistan
}

Correspondence: Muhammad Usman Munir

Department of Pharmaceutical

Chemistry, College of Pharmacy, Jouf

University, Sakaka, Aljouf 72388, Saudi

Arabia

Tel +966540980396

Email mumunir@ju.edu.sa

\begin{abstract}
The ongoing escalation of drug-resistant bacteria creates the leading challenges for human health. Current predictions show that deaths due to bacterial illness will be more in comparison to cancer in 2050. Irrational use of antibiotics, prolonged regimen and using as a prophylactic treatment for various infections are leading cause of microbial resistance. It is an emerging approach to introduce evolving nanomaterials (NMs) as a base of antibacterial therapy to overcome the bacterial resistance pattern. NMs can implement several bactericidal ways and turn into a challenge for bacteria to survive and develop resistance against NMs. All the pathways depend on the surface chemistry, shape, core material and size of NMs. Because of these reasons, NMs based stuff shows a critical role in advancing the treatment efficiency by interacting with the cellular system of bacteria and functioned as an antibiotic substitute. We divided this review into two sections. The first part highlights the development of microbial resistance to antibiotics and their mechanisms. The second section details the NMs mechanisms to combat antibiotic resistance. In short, we try to summarize the advances in NMs role to deal with microbial resistance and giving solution as antibiotics substitute.
\end{abstract}

Keywords: antibacterial materials, multidrug resistance, metallic nanoparticles, antibacterial effect, microbial resistance mechanism, bacterial biofilm, antibiotic substitute

\section{Introduction}

Antibiotics perform their action by restraining or eradicating pathogens in a bacteriostatic or bactericidal way, respectively. ${ }^{1}$ These drugs act through linkage with any essential compounds of microbial metabolism, thus preventing the formation of functional biological molecules in pathogens. ${ }^{2}$ However, microbes are developing resistance to antibiotics in the current scenario, significantly reducing their efficacy and failure of treatment. ${ }^{3}$ At present, ongoing escalation of drug-resistant bacteria creates the leading contests for human health. According to the reports, almost 2 million patients are suffering from antibiotic-resistant infections with nearly 23,000 deaths annually in the USA. ${ }^{4}$ According to $\mathrm{WHO}$, the death rate due to antibiotic resistance is more in developing countries than developed countries. WHO used the motto "no action today-no cure tomorrow" on World Health Day 2011, Current predictions show that deaths due to bacterial illness will be more in comparison to cancer in $2050 .^{5}$ Persistent drug therapy is needed in infections due to multidrug-resistant bacteria (MDR) which cause too much cost (as reported per year cost $\$ 55$ billion in the USA) and short patient compliance. ${ }^{6}$ Additionally, irrational use of antibiotics, prolonged treatment for MDR bacteria and 
used as a prophylactic treatment for various infections are leading cause of resistance. ${ }^{7}$ In USA hospitals, approximately $50 \%$ of Staphylococcus aureus (S. aureus) strains were resistant to methicillin, ie, methicillin-resistant S. aureus (MRSA). Escherichia coli (E. coli) resistance has observed for $17.3 \%$ of clinical infections against several antibiotics. Similarly, Enterococcus, Enterobacteriaceae, Pseudomonas aeruginosa (P. aeruginosa) and Acinetobacter have developed resistance against many classes of antibiotics. ${ }^{8-10}$

Antibiotics attack bacteria through several mechanisms like hindering the DNA, RNA and protein synthesis, biofilm formation and inhibition of cell wall synthesis. Conversely, an intrinsic talent of bacteria helps to change quickly by DNA transfer, ie, horizontal gene transfer, and mutations to overwhelm the antibiotic risks. ${ }^{11,12} \mathrm{~A}$ gene named as mecA is discovered in bacterial cells responsible for bacterial resistance against the antibiotics such as penicillin or penicillin-like antibiotics and methicillin. ${ }^{13}$ The single microbe can acquire drug-resistant genes from different bacteria to develop MDR, ie, superbug. MDR resistance mechanisms comprise of natural and synthetic classes of antibiotics. It has been found that New Delhimetallo-blactamase-1 (NDM-1) enzyme is accountable for the breakdown of $\beta$-lactam antibacterial and thus posing wideranging antibiotics ineffective to these bacteria. ${ }^{14} \mathrm{MDR}$ mycobacterium tuberculosis (MDR-TB) case reports describe the progressive resistance pattern against available drugs. ${ }^{15}$ Notably, $S$. aureus is a vital challenge against a wide spectrum of septicemias of healthcare and community. Antibiotic resistance (ABR) has become a global threat due to lack of new antibacterial agents and evolving resistance of MDR bacteria as shown in Figure 1. Thus promptly intensifying danger demands novel approaches for treatment in combatting resistant strains.

Nanomaterials (NMs) have caught the attention of researchers to overwhelm the bacterial resistance pattern. These provide a great platform to update physio-chemical properties of the materials resulting in more promising agents against bacteria. ${ }^{16}$ An increased pattern of research by scholars reveal that they are trying to provide a solution for bacterial resistance through nanomaterials as presented in Figure 2. Some kinds of NMs comprise polymeric NMs, liposomes, dendrimers of zinc oxide $(\mathrm{ZnO})$, silver oxide, gold, and solid lipid NMs. Some NMs directly get attach to the cell wall of microbes, hence there is no need for penetration into the cell. While metal oxide NMs show

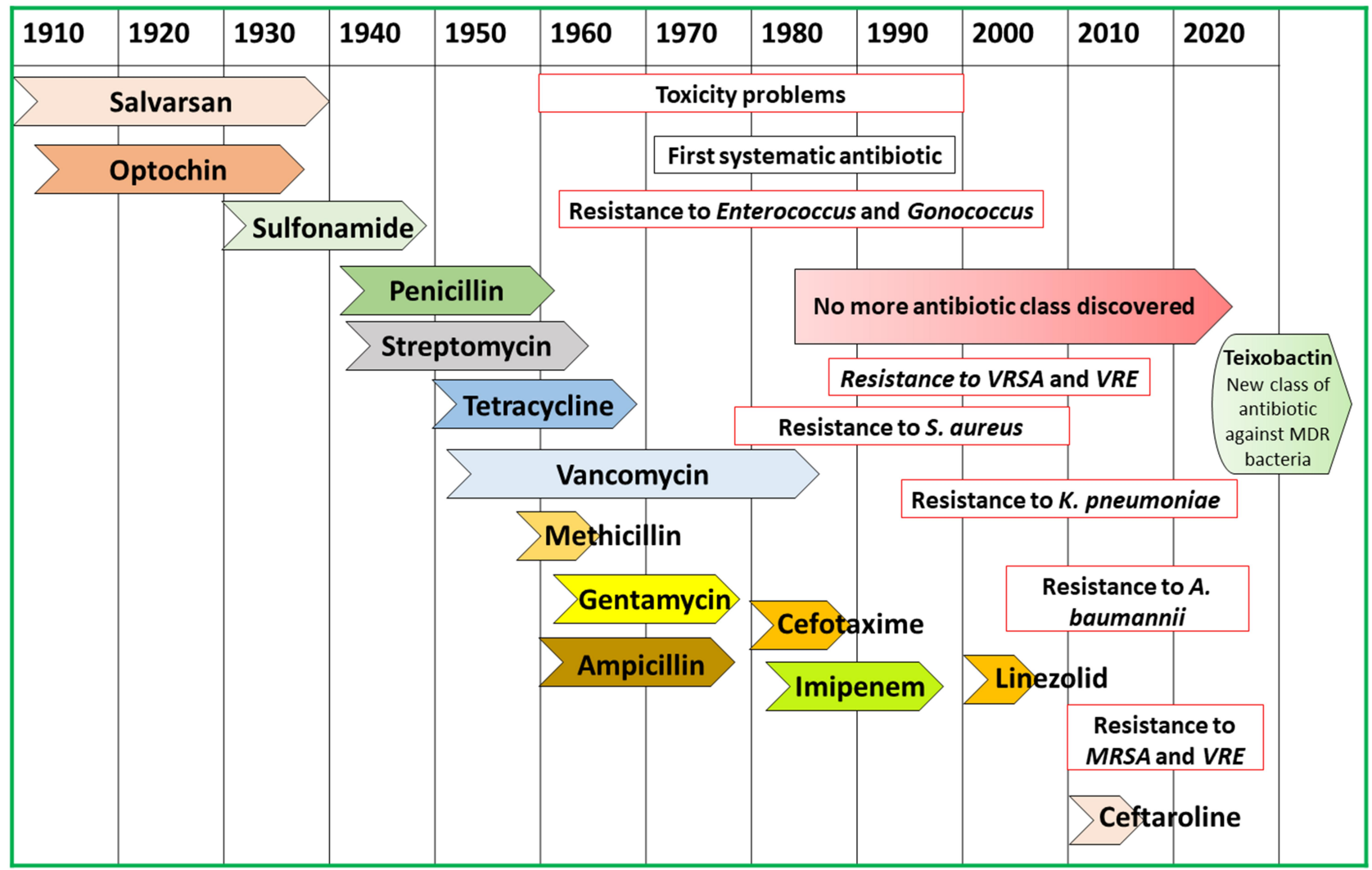

Figure I Antibiotics discovery with the development of resistance, overview of 20th and 2 Ist centuries. 


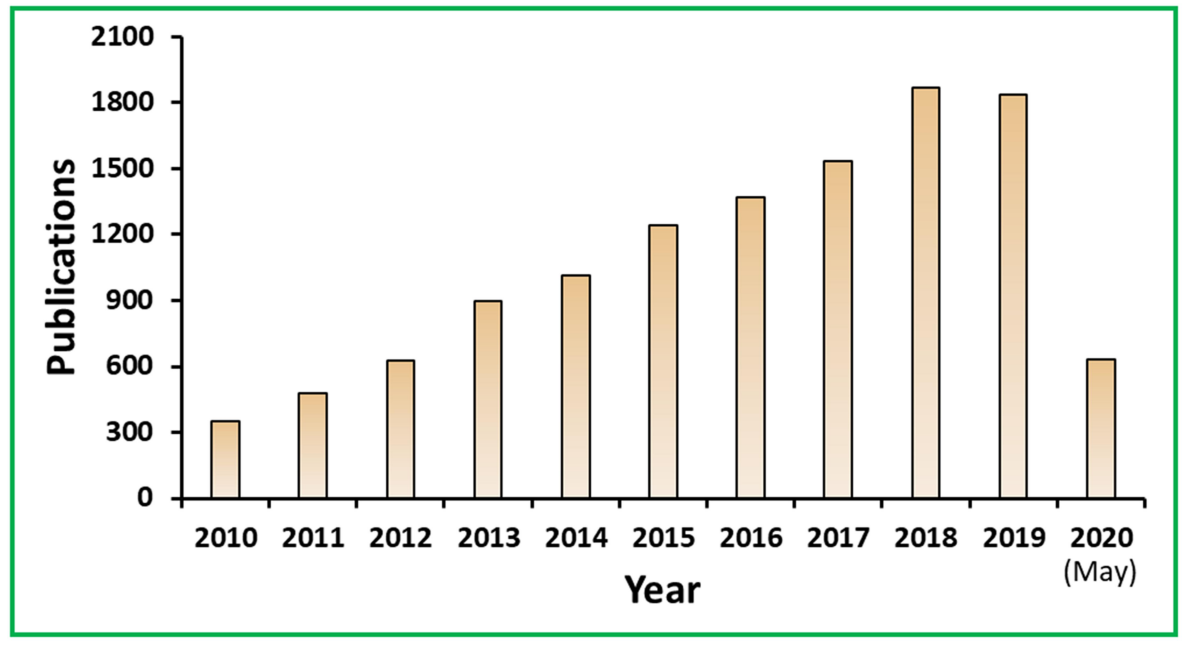

Figure 2 PubMed articles published on the topic of nanoparticles for antibacterial applications. The data was collected by using the keyword "antibacterial nanomaterials" in PubMed database about the articles published since 2010 .

microbicides properties through reactive oxygen species (ROS). ${ }^{17}$ Environmental friendly NMs abolish microbial membrane and making favorable to be used against MDR bacteria by adsorption, chemical conjugation, or physical encapsulation method. ${ }^{18} \mathrm{NMs}$ can implement several bactericidal ways and turn into challenging for bacteria to survive and develop resistance against NMs. All the pathways depend on the surface chemistry, shape, core material and size of nanomaterials. ${ }^{19}$ In addition to this, the synergistic antibacterial effect achieved by loading the drugs into NMs assists to cope up ABR. Because of these reasons, NMs based stuff show a critical role in advancing the treatment efficiency by interacting with the cellular system of bacteria and functioned as an antibiotic substitute.

It is an emerging approach to use NMs in antibacterial therapy to overcome the bacterial resistance configuration. ${ }^{20,21}$ We divided this review into two sections for easy understanding of the readers. The first portion confers the progress in microbial resistance to antibiotics with their mechanisms. These mechanisms include higher efflux and less drug uptake, expressing resistance gene, modification of antibiotics, antibiotics competitive inhibition, antibiotic tolerance, biofilms and swarming. Second section details the mechanisms of different NMs to combat bacterial resistance.

\section{Microbial Resistance to Antibiotics and Their Mechanisms Microbial Resistance Progression}

Drug resistance develops by following steps: Firstly, the microbes, starting gene expressing itself, possess the resistance gene and then microbes are chosen for which resistance gene is expressed. Initially, horizontal gene transfer occurs through transduction, conjugation and transformation, and a microbe develops resistance against sole or combination of drugs. Voluntary mutation of already existing genes also causes possession of resistance gene. $^{22}$ The bacteria having one more resistance gene results in multiple drug resistance. Resistance gene is expressed by a microbe when it is exposed to the drug. ${ }^{23}$

Another way of developing ABR is by using timedependent drugs with a long half-life, poor compliance of patients and long-term use of antibiotics. In comparison to microbicides, microbistatic drugs only inhibit microbial growth and develop significant resistance pattern whenever exposed to drugs. ${ }^{24}$ Inadequate doses or missing regular doses of antibiotics consequences in microbial exposure to the drug with incomplete removal. Such actions lead to the creation of selective pressure supporting resistance behavior. Those drugs that have small half-life reasons patient towards non-compliance due to quick elimination. The interval between two doses is short and microbes' extinction dose is large. ${ }^{25}$

Selective pressure produces, even the administered doses are according to schedule, because of the incidents happening in the interval of each dose. These consequences are the functions of variables known as $\mathrm{t}>$ minimum inhibitory concentration (MIC). It is the time per interval of doses where plasma drug concentration is more than the MIC. At this stage, the drug activity reaches at peak and chances of developing resistance are minimized, ${ }^{26}$ therefore, timedependent drugs having plasma concentration more than 
zero but below MIC will develop resistance as an outcome. It could be possible once the elimination half-life of an antimicrobial drug is long. Clindamycin, beta-lactams, macrolides except for azithromycin, ie, azalides and tetracycline's, etc., are the time-dependent antimicrobial drugs. ${ }^{27}$

In the case of concentration-dependent drugs, clinical consequences are functions of variables known as $\mathrm{C}_{\max } /$ MIC. It is the ratio of peak plasma concentration of drug during the interval to MIC. If this ratio increases above the target threshold value, antimicrobial action of drugs increases to a maximum as well as chances of resistance development lowers to a minimum and vice versa. Elimination half-life does not have any role in this case, so we can say it is independent of the half-life of drugs. ${ }^{28}$ Aminoglycosides, azalides involving azithromycin, quinolones, ketolides, and vancomycin (Van) are concentration-dependent antibiotics. ${ }^{29}$

\section{Microbial Resistance Mechanisms}

The microbes against antibiotics use several methods of developing resistance. Figure 3 presents a schematic to understand bacterial mechanisms of resistance.

\section{Higher Efflux and Less Drug Uptake}

Two main resistance methods include decreased uptake of an antibiotic and its elevated efflux. The drug level can be controlled in a microbial cell by less drug uptake or use of transmembrane efflux pump from normal to toxic level. Several microbes have escalated efflux or decreased uptake methods against various classes of antimicrobial drugs. ${ }^{30}$ The cell wall of gram-negative bacteria is made of peptidoglycan, around periplasmic space like $P$. aeruginosa, E.coli, etc. Less sensitivity of $P$. aeruginosa is endorsing the above methods. P. aeruginosa has inner

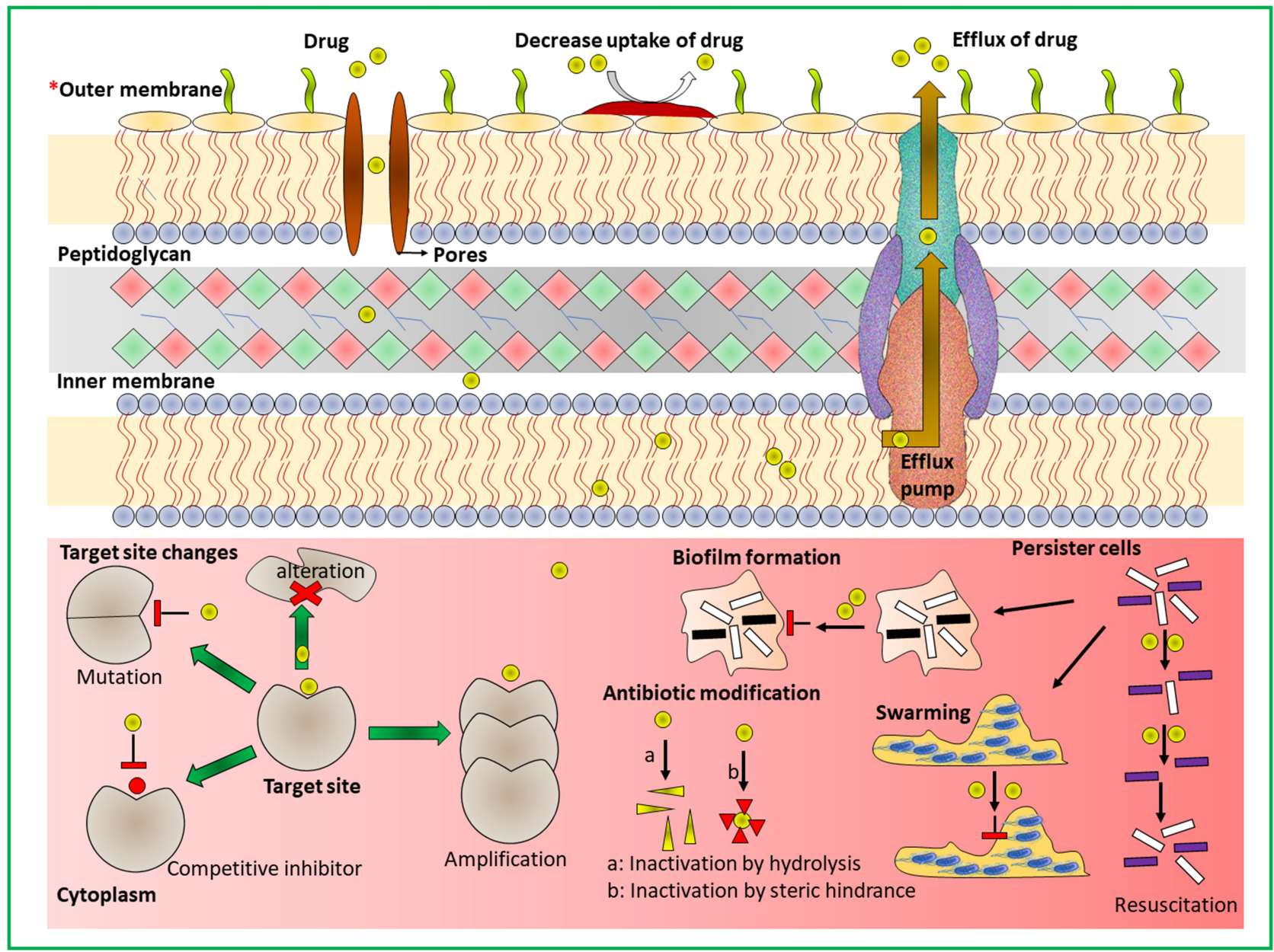

* Gram-negative bacteria have outer membrane and thin peptidoglycan, while gram-positive bacteria have thick peptidoglycan with no outer membrane.

Figure 3 Schematic showing multifarious mechanisms of microbial resistance to develop MDR like decrease uptake of drug, an efflux of drug, target site changes, antibiotic modification, persister cells, swarming and biofilm formation. 
membrane protein, ie, $\mathrm{H}^{+} /$drug antiporter protein attached to a linker protein in the periplasmic space. Regulatory protein suppresses the gene, which codes for efflux protein and resulting in mutation of this regulatory protein that causes overexpression of efflux protein and MDR of $P$. aeruginosa. $^{31}$

Similarly, a transmembrane proton gradient is utilized as a source of energy by minimum of nine pumps expressed by E. coli. This energy expels many antibiotics and results in $E$. coli resistance for numerous drugs. There are three families of efflux pumps depending upon proton; resistance nodulation cell division family (RND), small multidrug resistance family (SMR) and major facilitator superfamily (MFS). The supreme common pump is RND, known as AcrAB/TolC. ${ }^{32}$ In the case of drug-sensitive bacteria, expression of protein consisting of AcrAB/TolC pump is suppressed by acrR protein. Resistance in microbes triggers after drug efflux incidence because of pump protein expression. This occurs when the suppression created by acrR completed due to mutation in acrR gene. E. coli contains periplasmic space enclosed in the external and internal membrane. AcrB internal membrane protein of AcrAB/TolC pump is linked to a protein located in the periplasmic space, ie, AcrA protein that is bound to TolC external membrane protein. A pathway from the cytoplasm to extracellular space is created when TolC and AcrB are brought close to each other due to the conformational change of AcrA and resulting drug efflux. $^{33}$

Resistance gene is exhibited by several microbes, which permit higher efflux and low uptake of some antimicrobial drugs like streptogramins, sulfonamides, chloramphenicol, macrolides, tetracyclines, aminoglycosides, and quinolones. ${ }^{34-36}$ Genes that code for efflux pumps of tetracyclines are TetB, TetK, and TetA exhibited in both gram-negative and positive bacteria. Bacteria get these by transposons and horizontal transfer of gene on a plasmid. ${ }^{22}$ For instance; consider the presence of TetA efflux protein on transposon Tn10 that usually did not express due to TetR suppressor protein. Tetracycline behaves as an inducer linking itself with TetR suppressor protein and deactivates it. This transcript and translate TetA causes catalysis of efflux of tetracycline and ultimately resistance. ${ }^{37}$

Most gram-negative bacteria are resistant to fluoroquinolones and chloramphenicol due to increased efflux mechanism. Resistance to streptogramins like dalfopristin and quinupristin by Enterococcus faecalis (E. faecalis) also use this resistance method. Decreased uptake of antimicrobial drugs by gram-negative bacteria such as $P$. aeruginosa causes resistance against aminoglycoside. Resistance against vancomycin is caused by the escalating thickness of external membrane, ie, cell wall in the microbes. $^{22}$

\section{Substrate Modification}

Another method of creating resistance is modified substrate by expressing the resistance gene to which the drug usually bounds. The action of the drug reduced because its binding affinity for a modified substrate is less as compared to the original substrate. These genes cause resistance against drugs including aminoglycosides, beta-lactams, quinolones, linezolid, sulfonamides, tetracycline, rifampin, and vancomycin. For example, resistance against beta-lactams is caused by MecA resistance gene. This gene codes for modified penicillin-binding protein, ie, PBP2A which had a little binding attraction for beta-lactams and results tolerance. Penicillin-binding protein (PBP) is too expressed by $S$. pneumoniae having less affinity for the drug. ${ }^{38,39}$

VanA resistance gene causes resistance against vancomycin, ie, glycopeptides. Coding for D-alanine-D-lactate ligase is done by VanA gene and modifying terminal domain D-ala-D-ala of peptidoglycan precursor to D-alaD-lactate. Former is a substrate of vancomycin as well as PBP trans-peptidase domain. Resistance against vancomycin happens because it is binding for D-ala-D-lactate has 1000 fold low affinity compared to D-ala-D-ala. VanA gene is exhibited by vancomycin-resistant $S$. aureus (VRSA) as well as vancomycin-resistant Enterococcus (VRE). ${ }^{40}$ Expression of modified dihydropteroate synthetase (DHPS) enzyme causes resistance against sulfonamides because DHPS is a substrate for sulfonamides. This method is used by microbes like Neisseria meningitides ( $N$. meningitides), S. pneumoniae, E. coli and Streptococcus pyogenes (S. pyogenes). ${ }^{41}$

Quinolone resistance is due to modified DNA gyrase or topoisomerase IV as these enzymes are the substrate for quinolones. Normally, quinolones link with a substrate in gram-positive bacteria, ultimately deactivate it and coding for topoisomerase IV subunits are done by parE or parC genes. Any mutation in these genes results in modified topoisomerase IV responsible for resistance. Quinolones have low affinity for modified substrate and hence causes resistance. On the other hand, substrate, ie, DNA gyrase is deactivated by quinolones binding in gram-negative bacteria and coding for DNA gyrase subunits is done by gyrA 
or gyrB genes. Any mutation in these genes results in modified DNA gyrase with less affinity for quinolones and consequently, resistance is developed. ${ }^{42}$ In recent discoveries, binding of quinolones is inhibited after attachment of QnrA and QnrB (the plasmid-encoded proteins) with DNA gyrase and topoisomerase II. ${ }^{43}$

Coding for modified antimicrobial binding sites by the resistance gene is the mechanism used for resistance against rifampin, aminoglycosides, macrolides, linezolid, and tetracycline. For instance, macrolides binding site is situated on 23S rRNA of 50S ribosomal subunit. Coding for N-methyltransferase is done by all members of the resistance gene family, ie, erythromycin resistance methylase (Erm), present on transposons or plasmids. These members methylate the adenine locating near macrolide linking site, ie, adenine of domain $\mathrm{V}$ of $23 \mathrm{~S}$ rRNA of $50 \mathrm{~S}$ subunit of the ribosome. Methylation of adenine inhibits binding of macrolides and causes resistance. ${ }^{24,44}$ Aminoglycosides binding sites are present on $30 \mathrm{~S}$ subunit of ribosomes and any mutation in this ribosomal subunit results in the hindrance of aminoglycoside binding and eventually progress in resistance. For instance, a newly discovered gene present on plasmids methylate 16S rRNA of $30 \mathrm{~S}$ ribosomal subunit and generates aminoglycosides resistance. In addition, modification in the rpsL gene is responsible for resistance against aminoglycosides and can see in E. coli. Resistance to tetracycline is developed, when resistance genes, ie, TetL and TetM hinder the tetracycline binding to its linking point present on $30 \mathrm{~S}$ ribosomal subunit. ${ }^{26,45}$

\section{Modification of Antibiotics}

Microorganisms may indicate drug-resistant genes, which code for the enzyme modifying the antimicrobial drug and restrict its biological action. Microbes develop the resistance against aminoglycosides, macrolides, quinolones, chloramphenicol, streptogramins, tetracycline, and $\beta$-lactams by covalent modification of the drug. ${ }^{7}$

For instance, $\beta$-ring of $\beta$-lactam is hydrolyzed by $\beta$ lactamase enzyme, hence, therapeutic action is inactivated and generate resistant to beta-lactams. ${ }^{39}$ Resistance develops by transfer of horizontal gene of $\beta$-lactamase on plasmids or because of reduced activity of repressor protein restraining gene transcription of $\beta$-lactamases in bacterial chromosomes. Many distinct $\beta$-lactamases have revealed so far and classified by two different classification systems. The first classification system is a molecular classification system that classifies depending upon the sequence of amino acids and thus $\mathrm{A}, \mathrm{C}$ and $\mathrm{D}$ classes (serine hydrolases) are made. Class B involves metallic-enzyme, which catalyzes hydrolysis by employing zinc prosthetic group. The second classification is a functional classification system that classifies $\beta$-lactamases based on their target molecules and the molecules inhibiting them. It comprises cephalosporinase as class 1 , broad-spectrum $\beta$-lactamases and serine carbapenemases as class 2 and metallic $\beta$-lactamases as class 3 . Bush et al reported a progressively broad review about classification systems. $^{46}$

$\beta$-lactamase having carbapenemase action is currently discovered, ie, NDM-1. Several NMD-1 expressing bacteria are observed to be resistant against all IV antibacterial drugs being utilized to cure severe infections. ${ }^{47}$ In past, infections caused by NMD-1 expressing bacteria were common in India but now have disseminated throughout the world including the USA and UK. Researchers examined 180 specimens of Enterobacteriaceae expressing NMD-1 obtained from different countries patients like the UK, Pakistan, and India (comprising 36 and 111 samples of $E$. coli and $K$. pneumoniae, respectively). ${ }^{48} \mathrm{It}$ observed that many of these samples are tolerant to monobactam aztreonam, aminoglycosides, quinolones, tetracyclines and $\beta$-lactam antibiotics. The only narrow range of antimicrobials were sensitive to provided samples like tigecycline and colistin. ${ }^{48}$

Aminoglycoside resistance genes code enzymes are responsible for covalent modification of $\mathrm{OH}$ or $\mathrm{NH}_{2}$ groups and present on aminoglycoside. Its outcome is lowering its affinity to bind with $30 \mathrm{~S}$ ribosomal subunit and subsequently decreasing the antibacterial action. ACT N-acetyltransferase, while $\mathrm{OH}$ group is phosphorylated and adenylated by $\mathrm{APH}$ O-phosphotransferase and ANT O-adenyl transferase, respectively, acetylate $\mathrm{NH}_{2}$ group. ${ }^{49,50}$

\section{Antibiotics Competitive Inhibitor}

In this resistance mechanism, bacteria produce resistance against antibiotics by engineering a competitive inhibiting molecule particularly for each antibiotic. For instance, bacteria yield higher production of para-aminobenzoic acid (PABA) to advance sulfonamide resistance. PABA fights with sulfonamide for bacterial enzyme linking site DHPS, resulting sulfonamide resistance and this resistance method is employed by $N$. meningitidis and $S$. aureus. ${ }^{51,52}$

\section{Antibiotic Resistance of Inactive Persister}

Infected bacterial community exhibit metabolically inert persisters that may cause repetition of that infection after 
treatment and develop resistance to antibacterial substances. A minute fragment $\left(\sim 1\right.$ out of $10^{6}$ cells $)$ shifts toxin-antitoxin (TA) genes exhibition irregularly in bacterial infection and provokes the metabolic action to lower down or cease. Such cells are named as persisters and become more resistant to antibiotics by decreasing their metabolic activity. ${ }^{53}$ Consequently, the bacterial infected community presented to antibacterial drugs showed that many of them are sensitive to the drug, while some persisters stay not affected. This shows treatment completion for a certain infection. Sometimes, shifting of persisters to metabolic action occurs again and they restart their growth by the repetition of infection as outcome. ${ }^{54}$

\section{Bacterial Biofilms}

Bacterial resistance to exceptionally several antibiotics is due to biofilm formation that causes chronic infection regardless of antibacterial cure. ${ }^{55}$ There are five steps of biofilm formation; Firstly, protein molecule from the host (for example, tissue or blood proteins) attached to a liquid or solid planes like tissue of host or implanted device, thus, a layer is formed known as conditioning film. Secondly, the primary connection takes places when bacterial planktonic cell is attracted and attached to a conditioning film by hydrophobic, London dispersion, and electrostatic forces. After that, these cells undergo division with the recruitment of other planktonic cells and raising the bacterial population. In the next step, attachment takes place irreversibly once the quantity of bacterial cell is primarily attached community increases from a particular threshold. These cells shift on gene expression by quorum sensing, which results in the formation and secretion of extracellular polymeric substance (EPS) matrix. It assembles and localizes the community of bacteria. Mainly proteins and polysaccharides are present in EPS with DNA. Matrix gathers materials like debris, blood proteins, and minerals from the surrounding environment. EPS matrix undergoes hydration and thus its constituent includes approximately $95 \%$ of $\mathrm{H}_{2} \mathrm{O}$. Channels and pores are also a part of the matrix. Irreversible attachment of the cells occur with one another and with the plane on which they are lying by the help of the EPS matrix. In the fourth step, there is the formation of bacterial micro-colonies within the matrix, as the growth of biofilm occurs slowly. Finally, equilibrium has attained between biofilm growth and tiny particles detachment from the biofilm. A detachment of tiny particles consequent discharge of planktonic bacteria. Travelling of released planktonic bacteria may occur through the growth medium (host's blood) to the conditioning films on other planes to form new biofilms. EPS matrix preserve cells of bacteria from an extremely high amount of antibacterial compounds which results in chronic infection rather than cure. Accordingly, biofilm making bacteria is 1000 folds more tolerant to antibiotics as compared to bacteria without biofilm. ${ }^{55-57}$

The diffusion barrier for antibiotics is EPS matrix and rarely reaches deeply located bacteria, ie, within the EPS matrix and efficiently goes to superficially placed bacteria. ${ }^{58}$ Accordingly, pronounced antibiotic resistance appears in deeply placed bacterial cells, while giving low defense to apparent cells. EPS matrix enables to develop the resistance against modern antibiotics. It lowers bacterial cells amount exposed to antibiotic under MIC without lowering the amount exactly to zero. Diffusion of antibiotic inhibits by EPS matrix through various methods; initially, the matrix pore size is too small to inhibit movement of more than certain sized molecules including antibiotics reaching to bacterial cells. Secondly, the negatively charge of the matrix that inhibits antibiotic from influencing the cells of bacteria. Lastly, covalent modification of antibacterial drug by enzymes located within the matrix, resulting in deactivation of antibiotic action. ${ }^{59}$

EPS matrix acts as a barrier to the movement of nutrients and $\mathrm{O}_{2}$ and generates antibiotic resistance indirectly. Deeply located bacteria have less metabolic action and growth rate as compared to the exposed bacteria due to a low amount of nutrients and $\mathrm{O}_{2}$ reaching to them and decreasing their susceptibility to the antibiotic. Susceptibility of surface located bacteria is unvaried because they sustain normal growth rate and metabolic action. It is another way by which more resistance is provided to deeply existing bacterial cells and lower shield to exposed cells. ${ }^{60} P$. aeruginosa and $S$. aureus are biofilm-forming bacteria. Pathogenesis arises from bacterial biofilm causes various illnesses like otitis media, lung infections and gingivitis. $^{61}$

\section{Swarming}

Antibiotic resistance method that is deliberated to be a kind of multi-cellularity in microbes and works by the subsequent methods: Planktonic cells of bacteria distinguish into multiple flagellated elongated cells, named as swarm cells. These remain closeness to one another as well as drift on planes as one unit like a raft. Swarm cells sub-culturing in liquid medium causes their de-differentiation into planktonic bacteria having non-resistant 
behavior to antibiotics. ${ }^{62}$ Serratia marcescens, P. aeruginosa, Bacillus subtilis (B. subtilis), Burkholderia thailandensis, Salmonella typhimurium (S. typhimurium) and E. coli showed swarm cells and possess resistant to many antibacterial agents. ${ }^{63}$

\section{Nanomaterials Mechanisms to Combat Bacterial Resistance}

NMs possess different mechanisms to combat bacterial resistance. Initially, numerous NMs like chitosan-derived NMs, metallic NMs and nitric oxide releasing NMs apply multiple mechanisms to prevent the progress of resistance by pathogens. ${ }^{64,65}$ Similarly, resistance development can be prevented by encapsulating various antibiotics within same NMs. ${ }^{66,67}$ Existing tolerance mechanisms like lower uptake and higher drug efflux, intracellular bacteria and development of biofilm can also be inhibited through NMs. ${ }^{16}$ Antimicrobial drugs aimed at infectious area via NMs and assisting larger amount of dose to reach the diseased site. This way aids to suppress the resistance with fewer side effects to the patients. Figure 4 illustrates how nanomaterials help to fight against bacterial tolerance.

\section{Nanomaterials Having Multifarious Combating Tools}

Various kinds of NMs have been used to compete against microbial resistance. Many simultaneous methods resist tolerance to develop against NMs, as several instant mutations in the gene of a single cell of bacteria needed to become resistant.

\section{Nitric Oxide Releasing Nanomaterials (NO-NMs)}

Different mechanisms are used against micro-organisms by NMs which release NO resulting in the decreased possibility of developing microbial resistance. ${ }^{68} \mathrm{NO}$ released from NMs react with superoxide $\left(-\mathrm{O}_{2}\right)$ and reactive nitrogen oxide intermediates (RNOS) is formed through which NO applies antibacterial act. RNOS includes nitrogen dioxide $\left(\mathrm{NO}_{2}\right)$, dinitrogen trioxide $\left(\mathrm{N}_{2} \mathrm{O}_{3}\right)$, and peroxynitrite (-ONOO). When the amount of NO come to be greater than $1 \mathrm{mM}$, development of RNOS becomes adequate to act against microbes by multiple methods. ${ }^{69,70}$ 1) The reaction of RNOS may occur with bacterial protein residues of amino acid, like met, phe, cys, trp and tyr along with proteins present in the plasma membrane. 2) Nitrosative damage to DNA can be caused directly by RNOS. It involves removal of an amine group from guanine, cytosine, and adenine, breakage of strands, and a basic site formation. Elevated production of alkylating agents and hydrogen peroxide $\left(\mathrm{H}_{2} \mathrm{O}_{2}\right)$ can also be the cause of RNOS, destroying DNA. Cys residues of enzymes that repair DNA as DNA alkyl transferases, gets S-nitrosylated by RNOS and thus become hindered. 3) The reaction of RNOS with proteins prosthetic groups as heme and Fe-S groups can also occur. Enzymes like, CYP450 enzymes, guanylate cyclase, and nitric oxide synthetase (NOS) contain heme. Once their quantity becomes adequately significant, RNOS irreversibly linked to Fe (II) present in heme, and it results in heme ejection from the protein and reduction of $\mathrm{Fe}$ in bacteria. 4) Cellular respiration of microorganisms hindered by inactivation of zinc metalloproteins by RNOS. 5) Peroxidation of lipids caused by RNOS. S-nitrosothiols (RSNO) are powerful nitrosylating agents and synthesized when thiols react with NO. Thiol residues are nitrosylated by RSNO. Spores of Bacillus cereus have restrained by S-nitrosothiol through above-said method. An innate immune response can also be triggered in human host by NO. ${ }^{71}$

Nguyen et al reported the antibacterial effect of sole $\mathrm{NO}$ and combination action with a model antibiotic, ie, gentamicin in polymeric nanomaterials. They observed that NMs released both agents simultaneously and showed synergistic properties, decreasing the viability of planktonic cultures and $P$. aeruginosa biofilm by more than $95 \%$ and $90 \%$, respectively (Figure 5). ${ }^{70}$ Currently, no indications of bacterial tolerance are available and assumed reason is the use of numerous instantaneous NO methods against microbes. Moreover, self-generated and serial passage mutagenesis assays are utilized by recent research to check whether S. epidermidis, E. coli, P. aeruginosa, MRSA, and $S$. aureus can make tolerance for NO or not. There is no rise perceived in minimum inhibitory concentration (MIC), representing no possibility of development of microbial resistance. ${ }^{72}$ Some bacteria after exposed to NO reveal enzymes, which preserve them from nitrosative destruction in the host at the physiologic amount of NO. In K. pneumoniae, P. aeruginosa, S. typhimurium, E. coli, and $S$. aureus, flavohemoglobin enzyme expresses. In MRSA and MSSA strains of $S$. aureus, the expressed enzyme is lactate dehydrogenase. In $S$. typhimurium, E. coli, and P. aeruginosa, the expressed enzyme is DNA repair enzymes. ${ }^{73}$ At NOs physiologic quantity, the above-mentioned enzymes can preserve the bacteria but these enzymes proved inadequate at a high quantity of NO released by NO-NMs. 


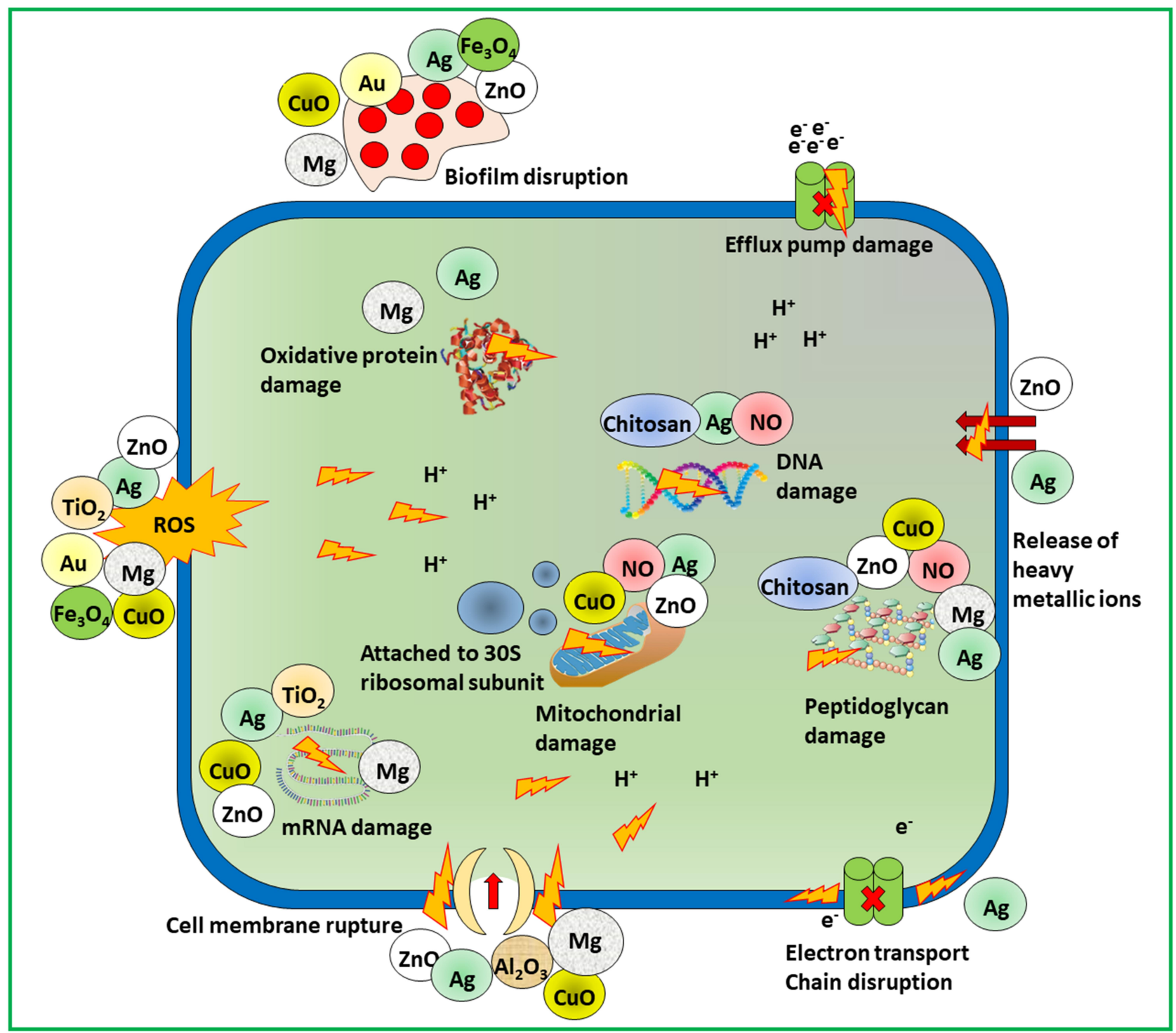

Figure 4 Scheme of mechanistic action of antimicrobial materials to combat microbial resistance.

NO-NMs are active against a wide range of bacteria and can act against drug-resistant bacteria by inhibiting their growth. These bacteria include $P$. aeruginosa, E. faecalis, $E$. coli, and $K$. pneumoniae. These microbes are killed in culture after reaction with NO-NMs quantity of $1.25-5$ $\mathrm{mM} .{ }^{74}$ When NO-NMs are applied on the skin or inside the lesions, in intramuscular abscesses, mice, and dermal abscesses, they lower the bacteria burden in lesions caused by MRSA. Infection caused by Trichophyton mentagrophytes and Candida albicans can be treated by NO-NMs. ${ }^{75}$

\section{Chitosan-Based Nanomaterials (CHT-NMs)}

CHT-NMs resist micro-organisms growth by applying numerous ways, so resistance to chitosan-NMs is not expected. ${ }^{76}$
Following are the mechanisms in combating bacterial resistance: 1) Removal of acetyl group done on CHT, a derivative of chitin, ie, elongated polymeric series of N-acetyl-glucosamine remnants. Thus, CHT is known to be polymeric extensive sequence having arbitrary residues of glucosamine and N-acetyl-glucosamine placed irregularly. ${ }^{77}$ CHT $\mathrm{C}_{2}$ amino group from which acetyl group has removed, have $\mathrm{pKa}$ value of $\sim 6.5$. Thus, protonation of many CHT groups occurred and at $\mathrm{pH}$ less than 6.5 they get a positive charge (occurs in infections of the epidermis). Antimicrobial action is observed when positive charge molecules attached with a microbial semi-permeable membrane and cell wall having a negative charge. This result in osmotic damage, higher penetrability through cell envelope of microorganisms, apparent 


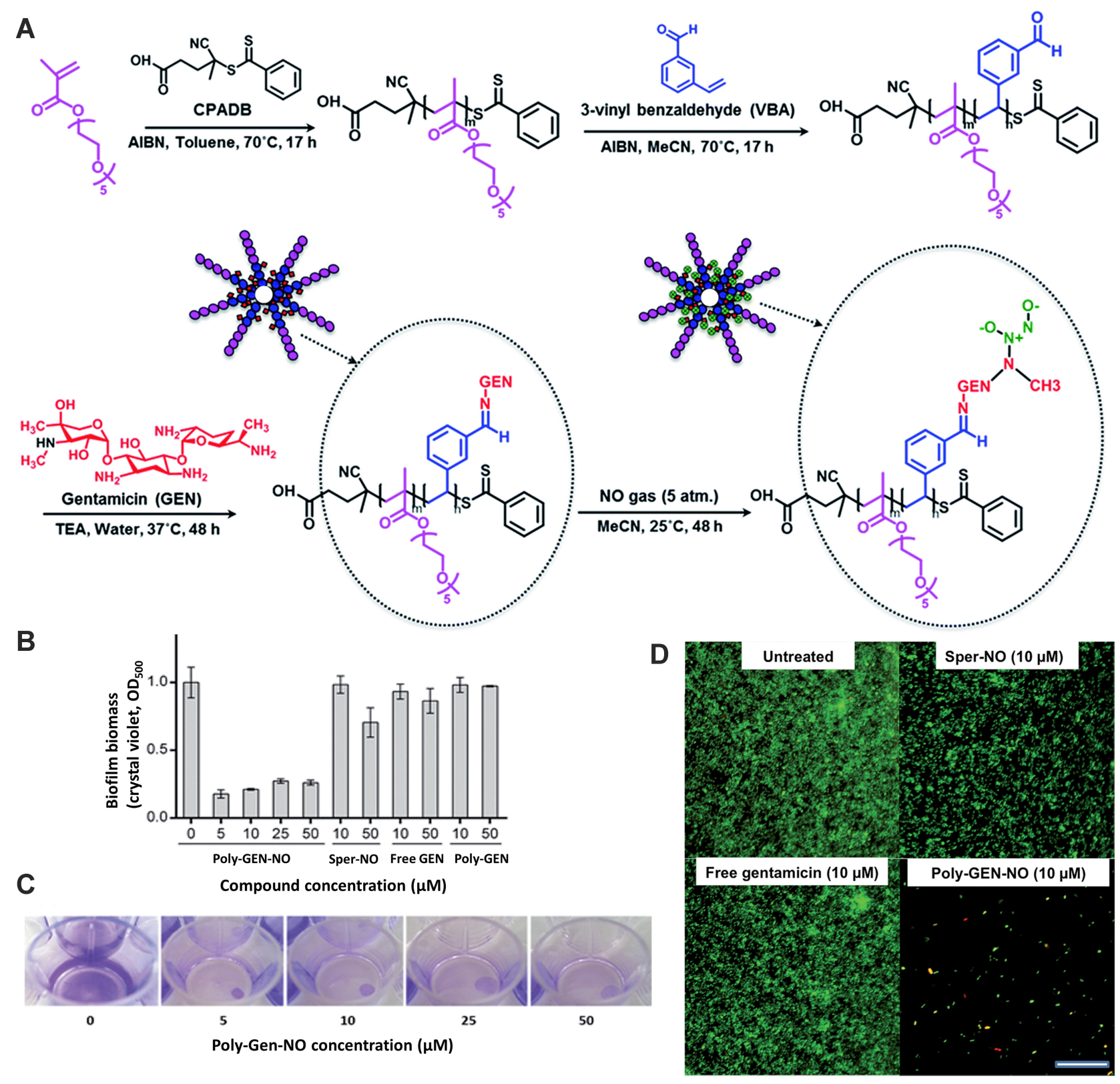

Figure 5 (A) Schematic approach for the preparation of gentamicin-NONOate nanoparticles via RAFT polymerization. (B and C) GEN-NO nanoparticles induced dispersal in P. aeruginosa biofilms. (B) Bacterial biofilms were grown in multi-well plates for $6 \mathrm{~h}$ in the absence of any treatment before being treated for a further $\mathrm{I}$ h with various concentrations (mM) of NO donor spermine NONOate (Sper-NO), free gentamicin or gentamicin-conjugated polymers (Poly-GEN) and GEN-NO nanoparticles (PolyGENNO). Biofilm biomass was analyzed by crystal violet staining. Error bars represent standard error $(n=2)$. (C) Stained biofilms treated with the indicated concentrations of GEN-NO nanoparticles. Note: concentration based on GEN, one mole of GEN-NO nanoparticles is equivalent to one mole of Sper-NO and gentamicin. (D) Representative confocal images showing P. aeruginosa biofilms stained with LIVE/DEAD kit. Biofilms were grown for $6 \mathrm{~h}$ and then treated with NO donor spermine NONOate (SperNO), free gentamicin, GEN-NO nanoparticles or left untreated for a further I h before staining. Viable and non-viable bacteria appear green and red, as well as those stained both green/red, respectively. Scale bar=50 mm. Note: concentration based on GEN, one mole of GEN-NO nanoparticles is equivalent to one mole of Sper-NO and gentamicin. Reproduced from Nguyen T-K, Selvanayagam R, Ho KKK, et al. Co-delivery of nitric oxide and antibiotic using polymeric nanoparticles. Chem Sci. 2016;7(2):1016-1027. ${ }^{70}$ Creative Commons license and disclaimer available from: https://creativecommons.org/licenses/by/3.0/.

movement of cytoplasm constituents, ie, proteins and ions. It is improbable to make tolerance against CHT-NMs mechanistic action. It is because of evolutionary protection of negative charge in the cell envelope of microorganisms, which are difficult to alter by a mutation in a single gene. 2) In case of fungal and bacterial cells, antimicrobial action presented by CHT through coherence with DNA resulting in hindrance to mRNA transcription and finally inhibition of protein translation. 3) The performance of metalloproteins may be less by CHT as it shows action by chelating metals. 4) Healing of 
wounds will be speedy because chitosan elevates the deposition of collagen III and fibroblast recruitment along with inhibition of inflammatory cytokines release. Hence, the risk of wound infections reduces with the increased healing rate. $^{78,79}$

Antibiotic action of chitosan can be enhanced by loading CHT into NMs. CHT application is hard in clinical settings due to poor solubility in-vivo. In physiologic environments, the solubility of chitosan is improved by encapsulating into NMs. ${ }^{80}$ Surface area-to-volume ratio increases by loading CHT into NMs, resulting in a boosted density of surface positive charges. Thus, association with negatively charged semi-permeable membranes and microbial cell walls become stronger and greater action takes place against microbes. CHT shows antimicrobial action against fungi, viruses and bacteria but this action against bacteria is less as compared to activity against viruses and fungi. ${ }^{81}$ As compared to CHT, antibiotics comprising doxycycline and acetic acid, NMs encapsulated with chitosan proved more efficient against $E$. coli and $S$. aureus. High molecular mass CHT-NMs and are low molecular mass CHT-NMs are more effective in gram-positive bacteria and gram-negative one, respectively. Gram-negative species have greater negatively charged envelope as compared to gram-positive, this is why CHT shows more efficacy against gram-negative bacteria. CHT amino group displaces $\mathrm{Mg}^{++}$and $\mathrm{Ca}^{++}$ions responsible for stabilization and co-ordination around lipopolysaccharide (LPS) present in gram-negative bacteria. Therefore, the penetrability of the outer membrane is increased by the release of lipopolysaccharide from the exterior membrane. ${ }^{82,83}$ Marangon et al reported the combination effect of CHT and rhamnolipid (RL) to boost antimicrobial activity. They also found the $\mathrm{pH}$ effect on CHT-NMs and CHT-RL-NMs. A schematic diagram of the synthesis of CHT-NMs and CHT-RL-NMs has been shown in Figure $6 .{ }^{84}$

\section{Metallic Nanomaterials (Metallic-NMs)}

There are various categories of metallic-NMs and each utilizes a variety of mechanistic tools to destroy or hinder the microbial growth, thus preventing resistance pattern. These comprise NMs of gold (Au), silver (Ag), zinc ( $\mathrm{Zn}$ ), copper $(\mathrm{Cu})$, magnesium $(\mathrm{Mg})$ and titanium (Ti). Combined treatment of bismuth NMs (Bi-NMs) X-ray is prospective in the treatment of drug-resistant bacteria. ${ }^{85,86}$ Among metallic-NMs, the NMs of aluminium oxide $\left(\mathrm{Al}_{2} \mathrm{O}_{3}-\mathrm{NMs}\right)$ are exemptions to assist drug resistance. ${ }^{87}$

\section{Silver Nanomaterials (Ag-NMs)}

Ag-NMs employ many antimicrobial mechanistic tools to cut the possibility of growth in bacterial resistance. The antimicrobial action of $\mathrm{Ag}$ is due to silver ions $\left(\mathrm{Ag}^{+}\right)$ formed by mixing silver in aqueous solution. ${ }^{88}$ The prepared $\mathrm{Ag}^{+}$ions apply antimicrobial act over numerous mechanisms. ${ }^{89}$ Firstly, $\mathrm{Ag}^{+}$ions react with phosphorus and sulfur groups containing proteins of the plasma membrane and bacterial cell wall. $\mathrm{Ag}^{+}$binds to negative parts of the cell membrane, making a hole and causes the cytoplasm content to sweep beyond the cell. The hydrogen ions gradient passes through the cell membrane, and occasionally causes the cell to die. If it does not happen, this association permits silver ions to penetrate via the plasma membrane and cell wall into cytoplasm resulting in stronger action by $\mathrm{Ag}^{+}$against bacteria. Gram-negative bacteria may be more sensitive to $\mathrm{Ag}^{+}$ions comparative to grampositive, for the reason that gram-negative bacteria contain a thin cell wall, providing $\mathrm{Ag}^{+}$suitable environment to invade bacterial cells. ${ }^{90}$ However, these bacteria have high vulnerability to $\mathrm{Ag}^{+}$as compared to gram-positive because $\mathrm{Ag}^{+}$attaches to LPS, having a negative charge, of gramnegative in contrast to peptidoglycan present in grampositive bacteria. Therefore, it was said that $\mathrm{Ag}^{+}$bounds to LPS and is less likely to penetrate the cell of gramnegative species comparative to cells of gram-positive bacteria. $^{91}$

$\mathrm{Ag}^{+}$put froths antimicrobial exertion within microbial cells: ${ }^{92}$ 1) $\mathrm{Ag}^{+}$prevents cytochrome of electron transport chain (ETC) microorganisms. 2) $\mathrm{Ag}^{+}$impasses as well as destroys RNA and DNA of microorganisms. 3) $\mathrm{Ag}^{+}$hinders DNA duplication by microorganisms, thus impeding division of cell. 4) $\mathrm{Ag}^{+}$provides ribosomal 30S subunits to prevent translation of protein. 5) $\mathrm{Ag}^{+}$ion is a source for the formation of reactive oxygen species (ROS) that have harmful effect to the cells of eukaryotic host and bacteria. $\left.{ }^{93} 6\right) \mathrm{Ag}^{+}$constrains the production of cell walls in case of gram-positive bacteria.

$\mathrm{Ag}^{+}$ions activity level against microbes is based on the form $\mathrm{Ag}^{+}$enters microorganisms. Metallic $\mathrm{Ag}$ has delicate antimicrobial activity. Besides, the protein adsorption at $\mathrm{Ag}^{+}$surface also hinders the bacterial growth. However, the addition of $\mathrm{Ag}^{+}$in NMs improves the action of $\mathrm{Ag}^{+}$ against microbes. ${ }^{88}$ The action of Ag-NMs against microbes is dependent on the quantity and morphology of the NMs. It is because the small volume and large surface of Ag-NMs have amplified the capability to permit in the cell wall peptidoglycan. Antibacterial efficiency of Ag-NMs increases when NMs have a smaller volume, 

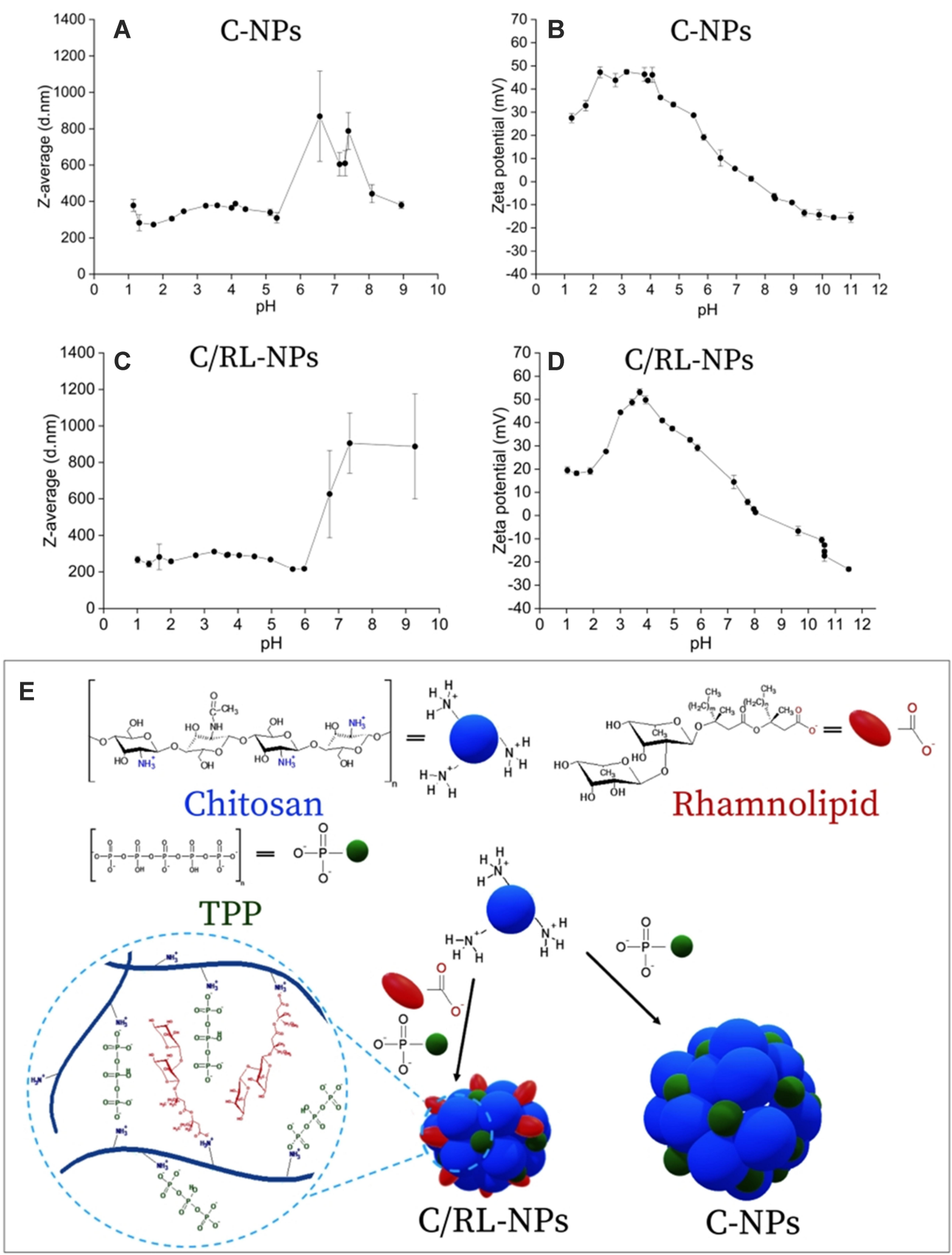

Figure 6 Effect of $\mathrm{pH}$ on the particle size (A) and zeta potential (B) of C-NPs and on the particle size (C) and zeta potential (D) of C/RL-NPs. Scheme of C-NPs and C/RLNPs synthesis (E). Data collected from DLS. Reprinted with permission from Marangon CA, Martins VCA, Ling MH, et al. Combination of rhamnolipid and chitosan in nanoparticles boosts their antimicrobial efficacy. ACS Appl Mater Interfaces. 2020;12(5):5488-5499. Copyright (2020) American Chemical Society. ${ }^{84}$ 
especially radium 10nm, and larger surface area. Ag-NMs having a shape of the greater surface area ensure higher $\mathrm{Ag}^{+}$release with superior antimicrobial action. ${ }^{94}$ Moreover, $\mathrm{Ag}$ may be oxidized to $\mathrm{Ag}^{+}$on $\mathrm{Ag}-\mathrm{NM}$ surface during synthesis and storage, therefore it is compulsory to create external $\mathrm{Ag}^{+}$layer on $\mathrm{Ag}-\mathrm{NM}$. Antibacterial efficiency declines once the Ag-NMs have greater volume and spherical or rod shape. ${ }^{91}$ Ligands may be added to AgNMs to enhance antibacterial activity through direct attachment of ligands to microbes and increases the uptake into microbial cell. Such substances are chitosan, polyethyleneimines, polyethylene glycol and glucosamine. ${ }^{95-97}$

Currently, although Ag has extensively used to fight against microbes, however, bacterial resistance against $\mathrm{Ag}^{+}$is occasional. This is attributed to the ability of $\mathrm{Ag}^{+}$ having multiple mechanisms of antimicrobial action, while sole antibiotics typically have one action mechanism against the bacteria. There are few bacteria tolerant to Ag$\mathrm{NMs}$ and $\mathrm{Ag}^{+}$due to modified cell membrane that reduces $\mathrm{Ag}^{+}$entry, and efflux pump causing $\mathrm{Ag}^{+}$outgoing from the cells. This resistance gene is revealed by using $\mathrm{Ag}^{+}$for long period. In addition, resistance gene expression disappears in the absence of $\mathrm{Ag}^{+}$. This shows that $\mathrm{Ag}^{+}$resistance gene expression may reduce the vitality of the bacterial evolution, causing the genes to be exhibited only in Ag presence instead of its lack. ${ }^{98}$ Wang et al used synchrotron radiations to describe the toxicity origin of Ag-NMs. Figure 7 reveals the mechanisms of Ag-NPs activity to human monocytes along with characterization and cytotoxicity of Ag-NMs. ${ }^{99}$ These NMs can also be synthesized from green source for antibacterial applications. ${ }^{100,101}$

Ag-NMs possess significant action against broad-spectrum microorganisms as well as against drug-resistant fungi, bacteria, and viruses. Researchers observed that Ag-NMs have prominent bactericidal action against MDR $P$. aeruginosa, erythromycin-resistant $S$. pyogenes and $E$. coli resistant ampicillin. ${ }^{67,90}$ The bactericidal outcome was similar regardless of whether it was tested drug-resistant or drug-sensitive bacteria. It indicates that antibiotic-resistant protein does not change their susceptibility to Ag-NM. ${ }^{102}$ In combination with antibacterial drugs, Ag-NMs boost the antibacterial activity of antimicrobial drugs significantly, eg, penicillin G, clindamycin, amoxicillin, vancomycin, and particularly erythromycin against $E$. coli and $S$. aureus. For instance, Wang et al studied the effect of Ag-NMs with an antibiotic like levofloxacin and reported the synergistic

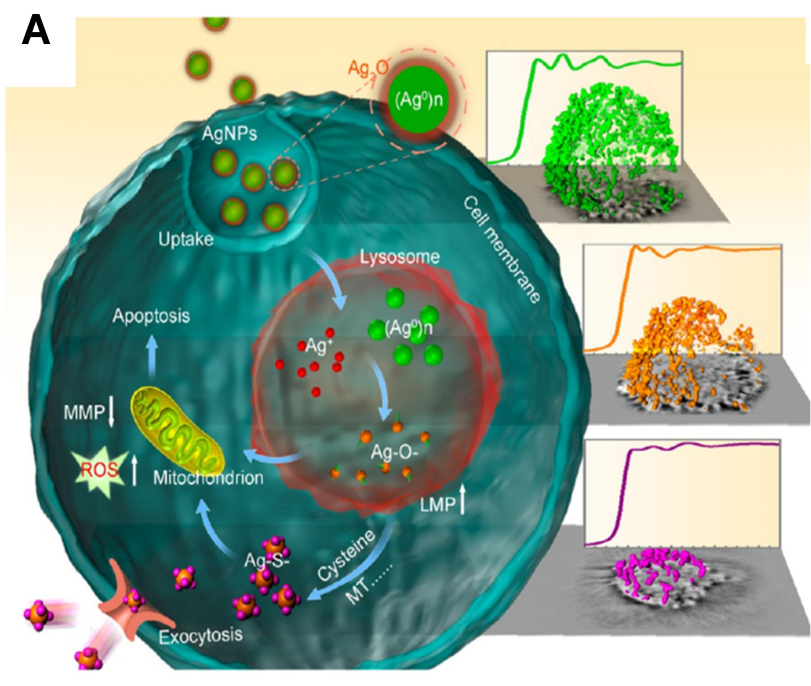

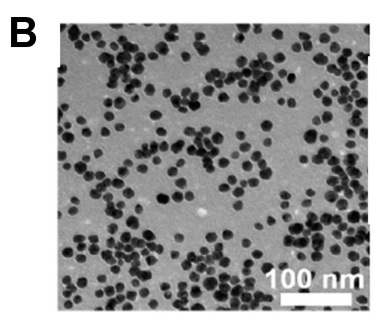

D

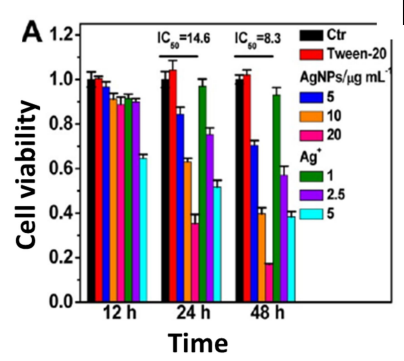

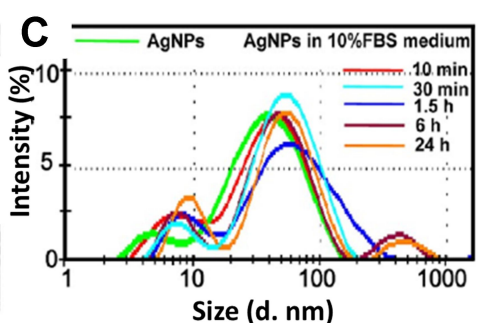

$E$

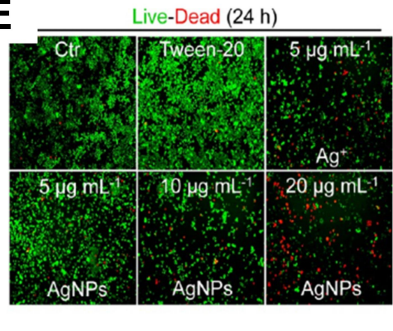

Figure 7 (A) Schematic diagram of chemical mechanism of Ag-NP toxicity to human monocytes (THP-I). Ag-NPs are internalized by cells and trafficked from engulfed vesicles to the lysosomes. Due to the acidic environment in the lysosome, Ag-NPs in the form of (Ag0)n are dissolved into Ag+ ions and then changed into $\mathrm{Ag}$-O-form possibly due to the binding of organic acid molecules. Dissolved silver increases LMPs that leads to the release of both dissolved silver and lysosomal contents to the cytoplasm. Then, both the increased LMPs and the released silver decrease the mitochondrial membrane potentials, which results in ROS generation and cell apoptosis. Meanwhile, the dissolved silver (Ag-O-) will interact with cysteinecontained proteins like metallothioneins, enzymes, etc. to become Ag-S- speciation, which may trigger mitochondrion-involved apoptosis. However, a part of Ag-S- form may be exported by the membrane transporters to reduce cytotoxicity. To understand the chemical origin of Ag-NP cytotoxicity, two advanced techniques are powerful to illustrate the dynamic processes of intracellular Ag-NPs in time and space. SR-TXM can in situ study the intracellular accumulation and exocytosis of Ag-NPs, while SRXANES is capable of revealing the chemical transformation of silver from the oxidation and degradation to the Ag-S- form. (B) TEM image of Tween-20 dispersed Ag-NPs. (C) Hydrodynamic size distributions of I0 $\mu g$ mL-I Ag-NPs during $24 \mathrm{~h}$ in ddH2O and 10\% FBS-supplemented RPMI 1640 medium. (D and E) Cytotoxicity of Ag-NPs and Ag+ ions. (D) Impacts of Ag-NPs, Ag+ ions, and the dispersant (Tween-20) on the mitochondrial dehydrogenase activity shown as cell viability vs the dose- and time-dependence. Data are shown as mean and standard deviation ( $n=4)$. $(E)$ Influence of Ag-NPs, Ag+ ions and Tween-20 on the percentage of live cells determined by Live-Dead assay. Reprinted with permission from Wang L, Zhang T, Li P, et al. Use of synchrotron radiation-analytical techniques to reveal chemical origin of silver-nanoparticle cytotoxicity. ACS Nano. 2015;9(6):6532-6547. Copyright (20I5) American Chemical Society. ${ }^{99}$ 
action with the safety profile in the animal study (Figure 8). ${ }^{103}$ A study presented that nano-articulated silver carbene complexes enveloped have harmful affect for MDR bacteria involving $P$. aeruginosa, $K$. pneumoniae, MRSA, Acinetobacter baumannii (A. baumannii) and Burkholderia cepacia. $^{104}$ Ag-NM has been revealed to ensure antiviral action against $\mathrm{HBV}$ and $\mathrm{HIV}-1 .{ }^{105}$

\section{Zinc Oxide Nanomaterials (ZnO-NMs)}

Different tools are being utilized by $\mathrm{ZnO}-\mathrm{NMs}$ to tackle microbes and making the resistant unlikely. ${ }^{106}$ These mechanisms include 1) Similar to other NMs, ZnO-NMs bind intensely to the bacterial membrane and destroys both lipids and membrane proteins. This results in higher penetrability of the membranes, the release of cytoplasmic substances from the cell and causing cell death. 2) $\mathrm{ZnO}-\mathrm{NMs}$ produces $\mathrm{Zn}^{+2}$ ions and ROS with hydrogen peroxide $\left(\mathrm{H}_{2} \mathrm{O}_{2}\right)$ that ruptures the bacteria cells. 3) When $\mathrm{ZnO}-\mathrm{NM}$ is coated with polyvinyl alcohol, it increases the permeability of the membrane and penetrates cell cytoplasm that results in oxidative stress. ${ }^{107-109}$ The toxicity of $\mathrm{ZnO}-\mathrm{NM}$ depends on its concentration. It has antibacterial action against MDR bacteria like MRSA and methicillin-resistant Streptococcus agalactiae. ${ }^{110,111}$ Pati et al stated the $S$. aureus existence in $\mathrm{ZnO}-\mathrm{NM}$ treated mice. Bacterial infection was caused in mice via intradermal route, and treatment was done with $\mathrm{ZnO}-\mathrm{NMs}$ on the same day $(S$. aureus $+\mathrm{ZnO}-\mathrm{NM})$ or $24 \mathrm{~h}$ after infection $(S$. aureus +24
h-ZnO-NM). Phosphate buffer saline (PBS) and ZnO-NM were employed as control with biopsy of mice skin with a histological look (Figure 9A and B). ${ }^{112}$

\section{Copper Oxide Nanomaterials (CuO-NMs)}

CuO-NMs utilize two methods in combating microbial resistance: ${ }^{113}$ 1) $\mathrm{Cu}$ reacts with carboxyl and amine groups at microbial cells. The microbes with larger density or having such groups on cell surface like $B$. subtilis are higher susceptible to these CuO-NMs. 2) At adequately excessive levels, $\mathrm{Cu}^{2+}$ ions cause the production of ROS that prevent both amino acid synthesis and DNA replication in microorganisms. ${ }^{114,115}$ Although CuO-NMs have a weaker antibacterial effect than Ag-NMs, these NMs have a broader spectrum of microbicide action to fungi particularly Saccharomyces cerevisiae along with microbes like Listeria monocytogenes, E. coli, and S. aureus. This microbicide action is the shape and concentration-dependent, ie, activity rises by increasing $\mathrm{Cu}-\mathrm{NMs}$ doses. ${ }^{116,117}$ Figure 10 illustrates the scheme of the bacteria-killing on a $\mathrm{Cu}-\mathrm{NM}$ incorporated mussel-inspired dendritic polyglycerol (MI-dPG) surface coating through a route of "attract-kill-release". ${ }^{118}$

\section{Titanium Dioxide Nanomaterials ( $\mathrm{TiO}_{2}-\mathrm{NMs}$ )}

These NMs also utilize two methods against microbes; as a result, the probability of developing resistance to $\mathrm{TiO}_{2}-\mathrm{NMs}$ is less. These mechanistic tools consist of the following: In

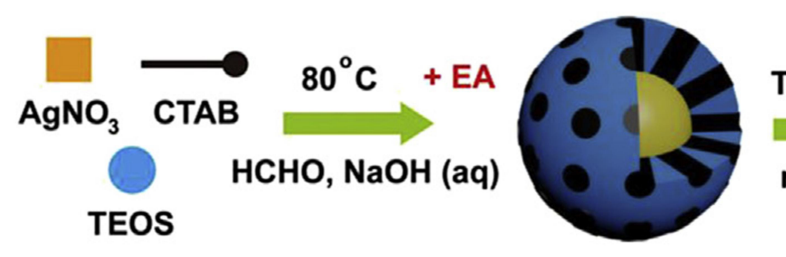

Ag@MSNs-CTAB
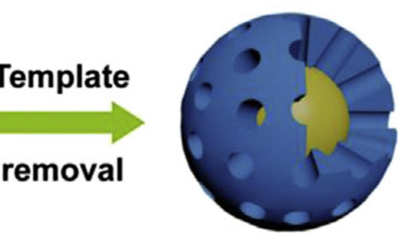

Ag@MSNs

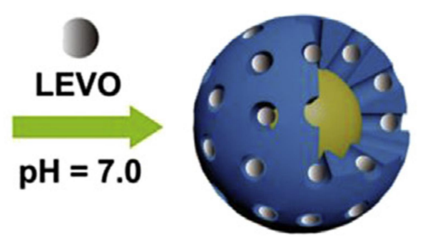

Ag@MSNs@LEVO
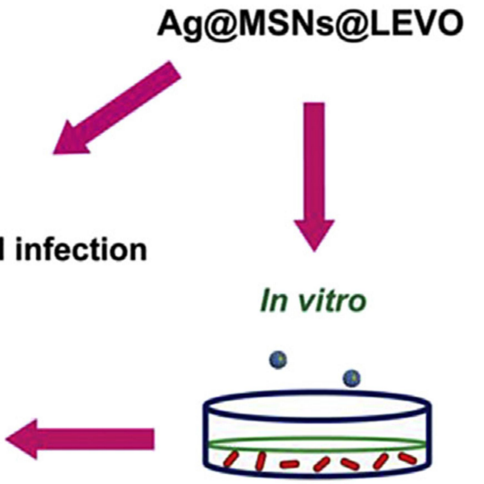

LEVO-resistant bacteria

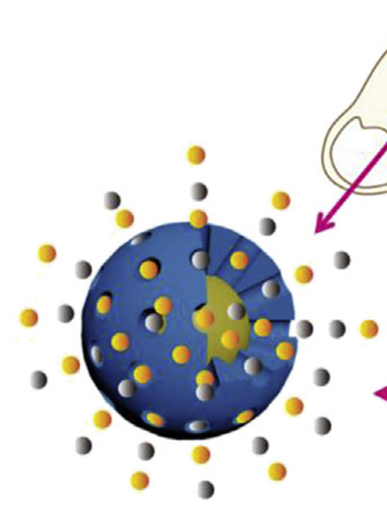

In vivo

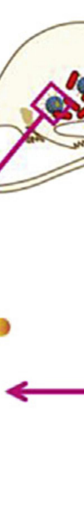

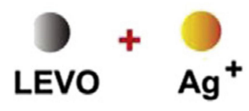

Sustained release

Figure 8 Schematic illustration of the fabrication of Ag@MSNs@LEVO nanoplatform and its application for a synergistic therapy of drug-resistant infections in vitro and in vivo. Reprinted from Biomaterials, Vol I0I, Wang Y, Ding X, Chen Y, et al, Antibiotic-loaded, silver core-embedded mesoporous silica nanovehicles as a synergistic antibacterial agent for the treatment of drug-resistant infections, Pages No.207-216, Copyright (2016), with permission from Elsevier. ${ }^{103}$ 


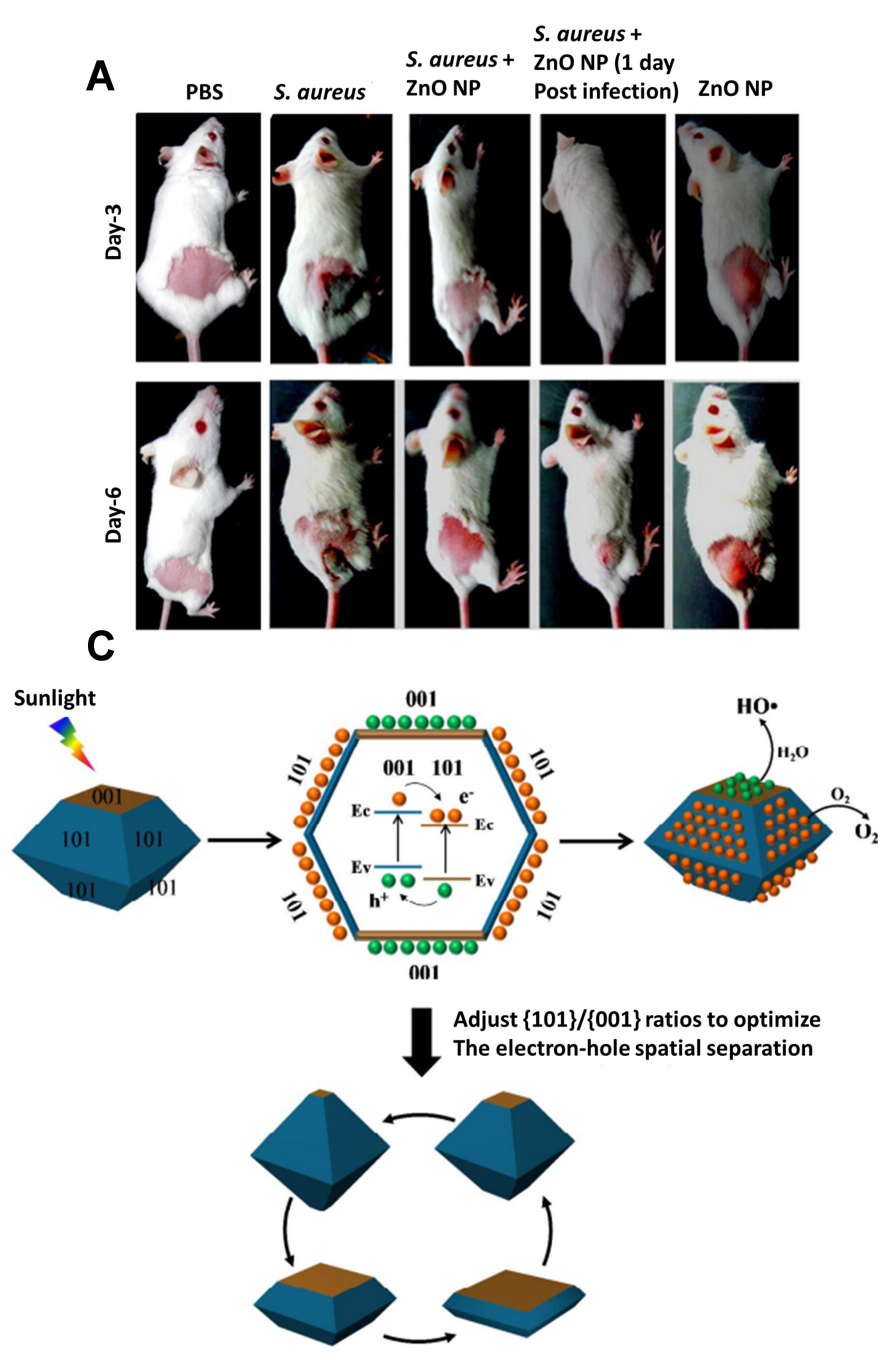

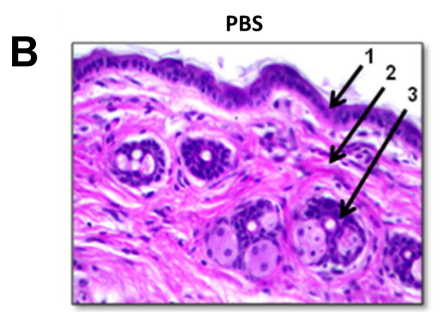

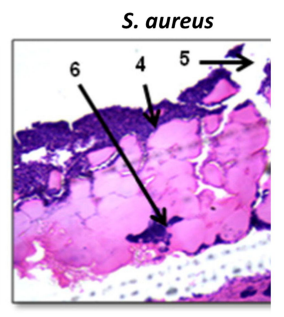

S. aureus $+\mathrm{ZnONP}$
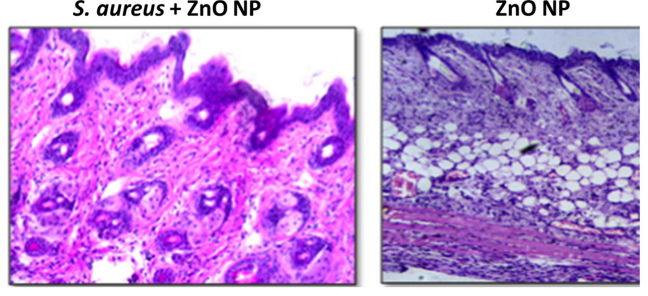

D

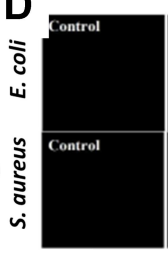

E
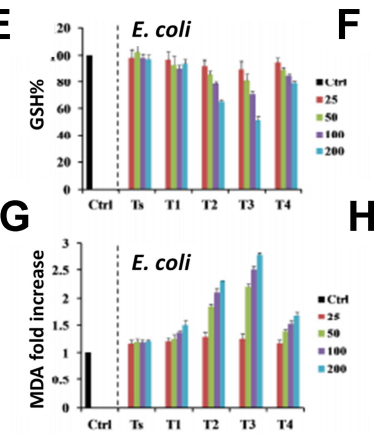

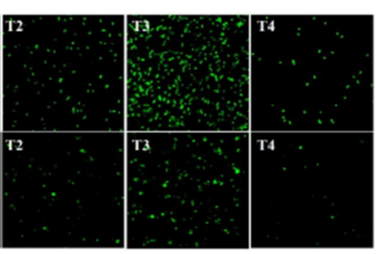

F $\left.{ }^{120}\right] \quad$ S. aureus
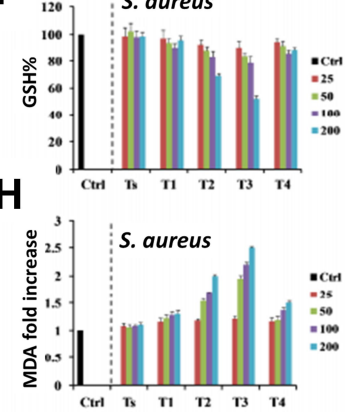

Figure 9 (A) Survival of S. aureus in ZnO-NP treated mice. Mice were infected intradermally with S. aureus and treated with ZnO-NPs simultaneously (S. aureus + ZnO NP) or I day after infection (S. aureus + Id ZnO-NP). Mice injected with PBS and ZnO-NP alone were used as control. Seven days after infection, skin lesions were cut, homogenized and bacterial count was determined by CFU assay. (B) Histological appearance of mice skin biopsy; PBS treated, S. aureus infected, S. aureus infected and ZnONP treated and only ZnO-NP treated. On day 6 , biopsy specimens were taken immediately after the termination of the experiment, fixed in $4 \%$ neutral buffered formalin and embedded in parafilm. The biopsy specimens were stained with hematoxylin and eosin. Numbered arrows indicate the following: I, epidermis; 2, dermis; 3, sebaceous gland; 4, bacteria; 5, disrupted epidermal layer; 6, polymorphous infiltrate, consisting of mononuclear cells including lymphocytes and neutrophils. Experiments were performed in triplicates, results are shown mean \pm SD; $* * * P \leq$ 0.00I. Adapted from Nanomedicine: Nanotechnology, Biology and Medicine, Vol I0/ Edition 6, Pati R, Mehta RK, Mohanty S, et al, Topical application of zinc oxide nanoparticles reduces bacterial skin infection in mice and exhibits antibacterial activity by inducing oxidative stress response and cell membrane disintegration in macrophages, Pages No.I195-1208, Copyright (2014), with permission from Elsevier. ${ }^{\prime \prime 2}$ (C) $\{10 \mid\}-\{00 \mid\}$ surface heterojunction-promoted electron-hole spatial separation. The conduction band and valence band edges of $\{00 \mid\}$ facet are higher than those of $\{|0|\}$ facets, facilitating electrons to transfer from $\{00 \mid\}$ to $\{|0|\}$ facets and holes from $\{|0|\}$ to $\{00 \mid\}$ facets under sunlight irradiation. The $\{|0|\} \mid$ $\{00 I\}$ ratio can be adjusted to optimize the electron-hole separation efficiency, maximizing the electron and hole accumulation on $\{\mathrm{IOI}\}$ and $\{00 \mathrm{I}\}$ facets, respectively. (D-H) Oxidative stress responses of E. coli and S. aureus bacteria treated or untreated with various TiO2 nanocrystals under simulated sunlight irradiation. (D) Fluorescence images of DCF-stained bacteria showing intracellular ROS production; Cellular GSH levels in E. coli (E) or S. aureus (F) determined by the GSH-Glo assay; Lipid peroxidation assessment of E. coli (G) or S. aureus $(\mathbf{H})$ based on a MDA method. Bacterial suspensions ( $1 \times 106 \mathrm{CFU} / \mathrm{mL})$ were incubated with $200 \mu \mathrm{g} / \mathrm{mL}$ of TiO2 nanocrystals for $2 \mathrm{~h}$ under simulated sunlight irradiation, followed by $6 \mathrm{~h}$ incubation at $37^{\circ} \mathrm{C}$ on a rotary platform at a $180 \mathrm{rpm}$. Adapted with permission from Liu N, Chang Y, Feng Y, et al. \{l0I\}-\{00I\} Surface heterojunction-enhanced antibacterial activity of titanium dioxide nanocrystals under sunlight irradiation. ACS Appl Mater Interfaces. 2017;9(7):5907-5915. Copyright (20I7) American Chemical Society. ${ }^{124}$

photocatalysis, $\mathrm{TiO}_{2}$ creates ROS containing $\mathrm{OH}$ and $\mathrm{H}_{2} \mathrm{O}_{2}$ radicals after exposure to radiation near-UV region. Once illuminated $\mathrm{TiO}_{2}$ becomes closed to microbe, ROS ruptures the membranes of bacterial cells, compromising the membrane permeability, intruding oxidative-phosphorylation, and occasionally producing cell impairment. ${ }^{119,120} 2$ ) In the case of irradiation absence, $\mathrm{TiO}_{2}-\mathrm{NM}$ still has a bactericidal outcome and suggests that it utilizes other antimicrobial methods, not linked to photocatalysis, which had not been discovered so far. ${ }^{121} \mathrm{TiO}_{2}$-NM kills the bacteria in the following decreasing order E. coli, P. aeruginosa, S. aureus, Enterococcus faecium, and C. albicans. ${ }^{122-124}$ Additionally, $\mathrm{TiO}_{2}$-NMs are effective to microbes in following decreasing order viruses, bacterial cell wall and spores of bacteria. ${ }^{125}$ These NMs can make different composites with other material for antimicrobial applications. ${ }^{126-128}$ 

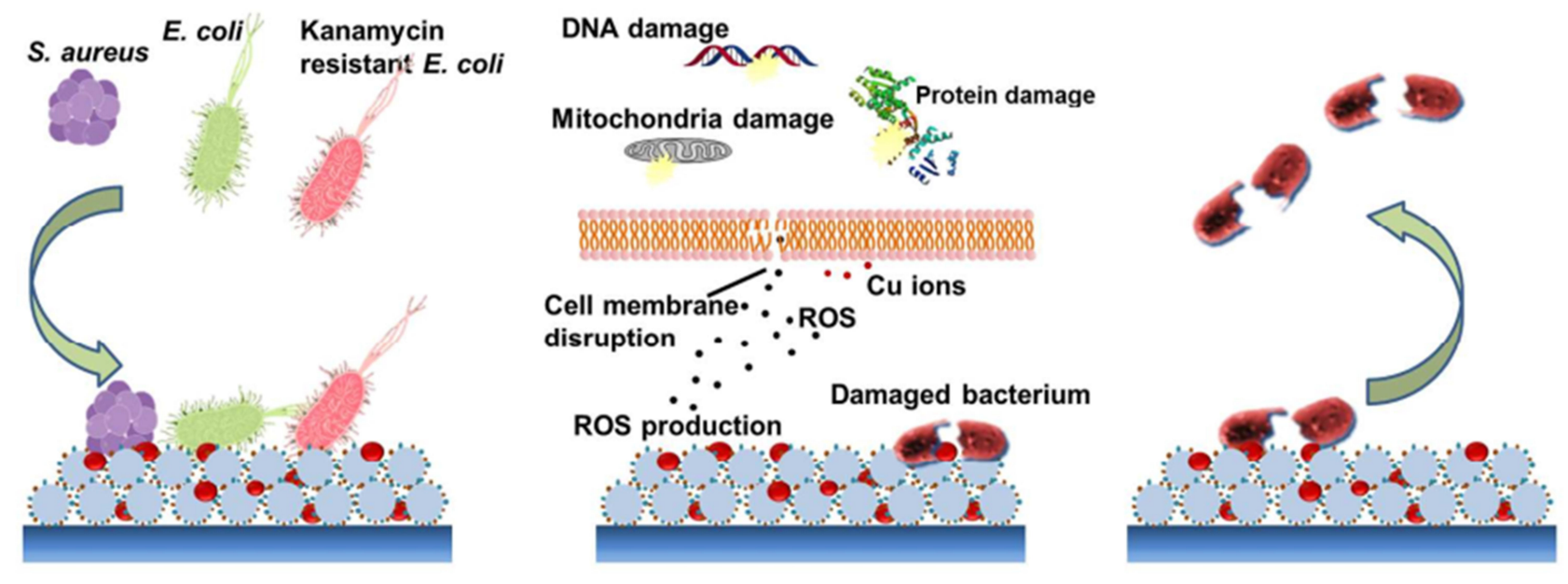

Figure 10 Schematic illustration of the contact killing of bacteria on a Cu-NP incorporated MI-dPG surface coating via the "attract-kill-release" route. Reprinted with permission from Li M, Gao L, Schlaich C, et al. Construction of functional coatings with durable and broad-spectrum antibacterial potential based on mussel-inspired dendritic polyglycerol and in situ-formed copper nanoparticles. ACS Appl Mater Interfaces. 2017;9(40):354II-354I8. Copyright (2017) American Chemical Society. ${ }^{18}$

Liu et al reported that $\mathrm{TiO}_{2}\{101\}$ and $\{001\}$ surfaces contain stunned conduction and valence bands. The formation of $\{101\}-\{001\}$ surface hetero-junction can quick photo-generated electron to favorably transmission from $\{001\}$ to $\{101\}$ sides, while the dumps move in the opposed direction that leads to electron-dump threedimensional separation. It ultimately produces more ROS and offers significant antimicrobial action as compared to spherical $\mathrm{TiO}_{2}-\mathrm{NMs}$ (Figure 9C). They testified the E. coli and $S$. aureus response to oxidative stress by treating with $\mathrm{TiO}_{2}$-NMs in imitated sunlight radiation and comparing with the control (Figure 9D-H). ${ }^{124}$

\section{Magnesium Nanomaterials (Mg-NMs)}

Mg-NMs may include NMs of Mg-halogen ( $\left.\mathrm{MgX}_{2}-\mathrm{NMs}\right)$ and magnesium oxide NMs (MgO-NMs), utilize several antimicrobial methods, which makes their resistance suspect: 1) As a rule, metal halide complexes hinder certain microbial enzymes of bacterial cells. 2) Mg-halogen can cause the development of ROS that causes lipid peroxidation in the membrane of cells of microbes affecting the cytoplasmic cell content outside. ${ }^{129}$ 3) $\mathrm{MgF}_{2}-\mathrm{NMs}$ induce peroxidation of lipid passing via microbial cell membrane, finally resulting in a decrease in $\mathrm{pH}$ of cytoplasm, which increases the potential of the membrane. $\mathrm{MgF}_{2}-\mathrm{NMs}$ prevent the development and manufacture of biofilms of $S$. aureus and E. coli. ${ }^{130}$ 4) Distinct from others, $\mathrm{MgO}$ action against microbes acts by adsorbing molecules of halogen on the surface of $\mathrm{MgO}$. Packing of $\mathrm{MgO}$ in $\mathrm{MgO}-\mathrm{NM}$ raises the number of halogen molecules that may adsorb in $\mathrm{MgO}$ up to five times, which enhances the microbicide action of halogens. ${ }^{131}$ The $\mathrm{Cl}_{2}$ and $\mathrm{Br}_{2}$ with MgO-NMs showed greater bactericidal activity against Bacillus megaterium and E. coli, although less for B. subtilis endospores. $^{132}$

\section{Gold Nanomaterials (Au-NMs)}

Au-NMs can be prepared by several strategies provided in the earlier reports. ${ }^{133,134} \mathrm{Au}-\mathrm{NMs}$ do not possess antibacterial activity alone but conjugated with antibiotic or polymer they exhibit antibacterial property. ${ }^{135,136}$ Brown et al testified that ampicillin bounded to the gold-NMs surface (Au-NM-AMP) abolished much bacterial resistance to drugs, involving Enterobacter aerogenes, P. aeruginosa, MRSA and E. coli. ${ }^{93}$ There are different characteristics of $\mathrm{Au}-\mathrm{NMs}$ which help to activate and enhance their antimicrobial activities by conjugating with antimicrobial substances. ${ }^{137}$ Antibiotics like kanamycin, levofloxacin have been conjugated with Au-NMs for improved antibacterial activity. ${ }^{138,139}$ Many scholars believe those bacteria that could not do endocytosis have not taken up by $\mathrm{Au}$ NMs. Moreover, cell wall inhibitor antibiotics like ampicillin penetrates the cell walls of gram-negative and grampositive bacteria to give antibacterial action. Therefore, ampicillin existence on gold NMs exterior permits AuNM-AMP to come into the bacterial cell. Scientists are unsure about the two methods that work together against bacteria. First, the existence of many molecules of ampicillin on Au-NMs surface permits Au-NM-AMP to suppress the elevated amount of $\beta$-lactamases. Secondly, AuNM-AMP hinders a transmembrane pump, which triggers drug molecule outflow from bacterial cell. ${ }^{140}$ 
Functionalization of NMs enables them a potent tool in penetrating cell membrane of bacteria. In ground-breaking results of functionalized NMs having antibacterial action, $\mathrm{Gu}$ et al produced Au-NMs functionalized with vancomycin (Van) against VRE. ${ }^{141}$ They synthesized Au-NMs of 5 $\mathrm{nm}$ and conjugating with bis (Van) cystamide by Au-S bond, and results in approximately 61 Van molecules per NM (Figure 11). The antimicrobial activity of Van-capped Au-NMs (Van@Au-NMs) was estimated by calculating their MICs that is needed to prevent the growth of the bacteria. Van@Au-NMs and sole Van presented MIC of 2-4 $\mathrm{mg} / \mathrm{mL}$ and $64 \mathrm{mg} / \mathrm{mL}$ against VRE, respectively.

Zhang's group worked on the drug release from $\mathrm{Au}-$ NMs triggered by a bacterial toxin, stabilized by liposomes, to treat bacterial problems as shown in Figure 12A. Van@liposomes have protected by absorbing Au-NMs coated with chitosan (AuCHT) onto their exterior to avoid from merging with the membrane of bacteria or with each other. When the AuCHT stabilized liposomes (AuCHT-liposomes) bump into microbial toxins, pores made in the liposomal membrane by the toxins, so the loaded drug is released. It results in successively hinder or eradicate the bacterial growth responsible for the secretion of the toxins. They determined the surface zeta potential of AuCHT, sole liposome and AuCHT-liposome as presented in Figure 12B. ${ }^{142}$ Grzybowski's group tuned the surface charge of Au-NMs to get mixed-charge Au-NMs because these are more suitable against gram selective bacteria. Figure $12 \mathrm{C}$ and $\mathrm{D}$ illustrates the synthesis scheme of mixed-charge TMA/MUA NMs (TMA; trimethyl ammonium chloride, MUA; mercaptoundecanoic acid), and charge polarities of NMs calculated by zeta potential, respectively. They also performed the microscopic studies of bacteria, which were treated with different mixedcharge NMs as shown in Figure 12E. ${ }^{143}$

\section{Bismuth Nanomaterials (Bi-NMs)}

Bi-NMs are significantly potent against drug-tolerant bacterial strains. ${ }^{144}$ There are different ways to prepare BiNMs depending on the size and shape of NMs. ${ }^{145}$ For optimum antibacterial activity, Bi-NMs should be synthesized with controlled morphology and size. ${ }^{146}$ Different from visible, topical, or ultraviolet radiation therapy, $\mathrm{X}$-rays may influence and destroy bacterial infections in the dermis. Bi-NM utilization reduces the amount of radiation required to eradicate the bacteria, probably restraining harmful to human host cells. When X-rays radiate bismuth, it releases electrons by a photoelectric effect with

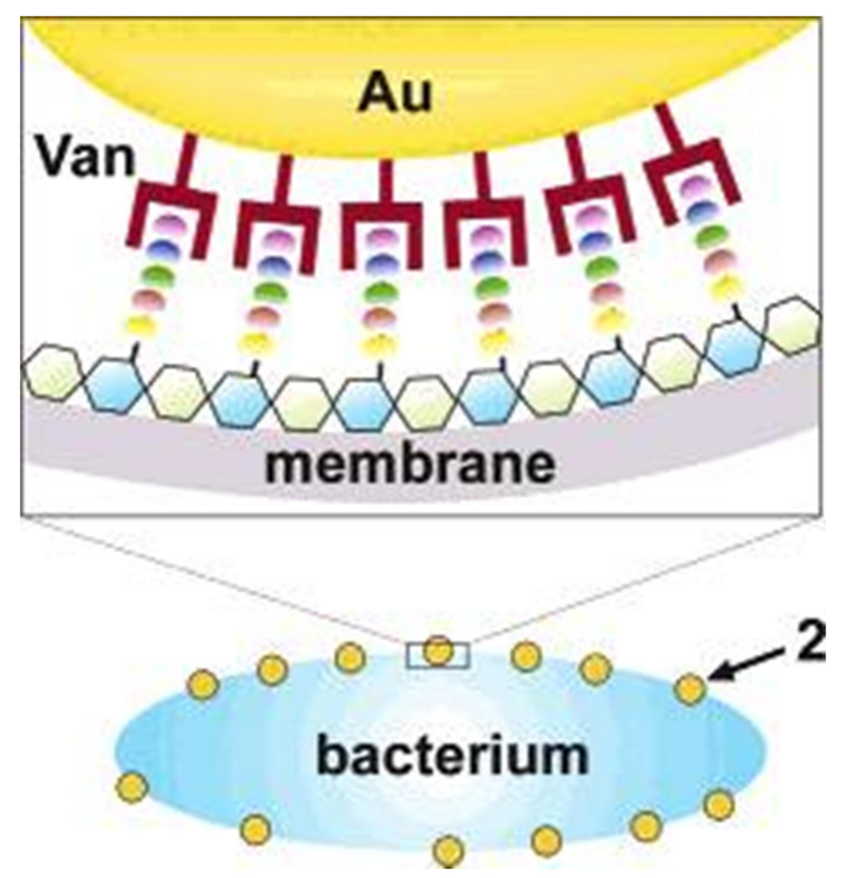

Figure II Illustration of a possible multivalent interaction between a Van-capped Au nanoparticle (2) and a VanA genotype VRE strain (hexagons: glycosides; ellipses represent the amino acid residues of the glycanpeptidyl precursor with different colors: L-Ala (yellow), D-Glu (orange), L-Lys (green), D-Ala (blue), and D-Lac (purple)). Reprinted with permission from Gu H, Ho PL, Tong E, Wang L, Xu B. Presenting vancomycin on nanoparticles to enhance antimicrobial activities. Nano Lett. 2003;3(9):|26I-1263. Copyright (2003) American Chemical Society. ${ }^{141}$

the formation of free radicals. The electrons and free radicals mutually destroy the DNA of bacteria steadily. ${ }^{86}$ Conjugation of Bi-NM with antibiotics to the object microbe more reduces the average distance between $\mathrm{Bi}$ $\mathrm{NM}$ and the cells of bacteria, so further enhancing the bactericidal action. ${ }^{147}$ Bi-NM radiation therapy is potent against $P$. aeruginosa of MDR, the most usual gram-negative bacterium that causes infections in hospitalized patients and utilized as the MDR model. In research, Biderived NM with polyclonal antibodies to P. aeruginosa had put-in the MDR-P. aeruginosa culture, subsequently low dose X-ray irradiation. ${ }^{86}$

\section{Aluminium Oxide Nanomaterials $\left(\mathrm{Al}_{2} \mathrm{O}_{3}-\mathrm{NMs}\right)$}

Alumina or $\mathrm{Al}_{2} \mathrm{O}_{3}-\mathrm{NM}$ is sort of metallic NMs, which can raise the possibility of developing resistance to the drugs. It is noted that $\mathrm{Al}_{2} \mathrm{O}_{3}-\mathrm{NMs}$ can penetrate the E. coli cytoplasm to exert the toxic effect. ${ }^{148}$ Whereas a high concentration of $\mathrm{Al}_{2} \mathrm{O}_{3}-\mathrm{NM}$ ruptures the bacterial cell wall but reveals a non-significant bacterial growth inhibition. ${ }^{20}$ A study showed that $\mathrm{Al}_{2} \mathrm{O}_{3}$-NM raises the hazard of horizontal transmission of antibiotic genes by a factor of 200 when conjugated from E. coli to salmonella. Consequently, bacteria are more likely to obtain one or 

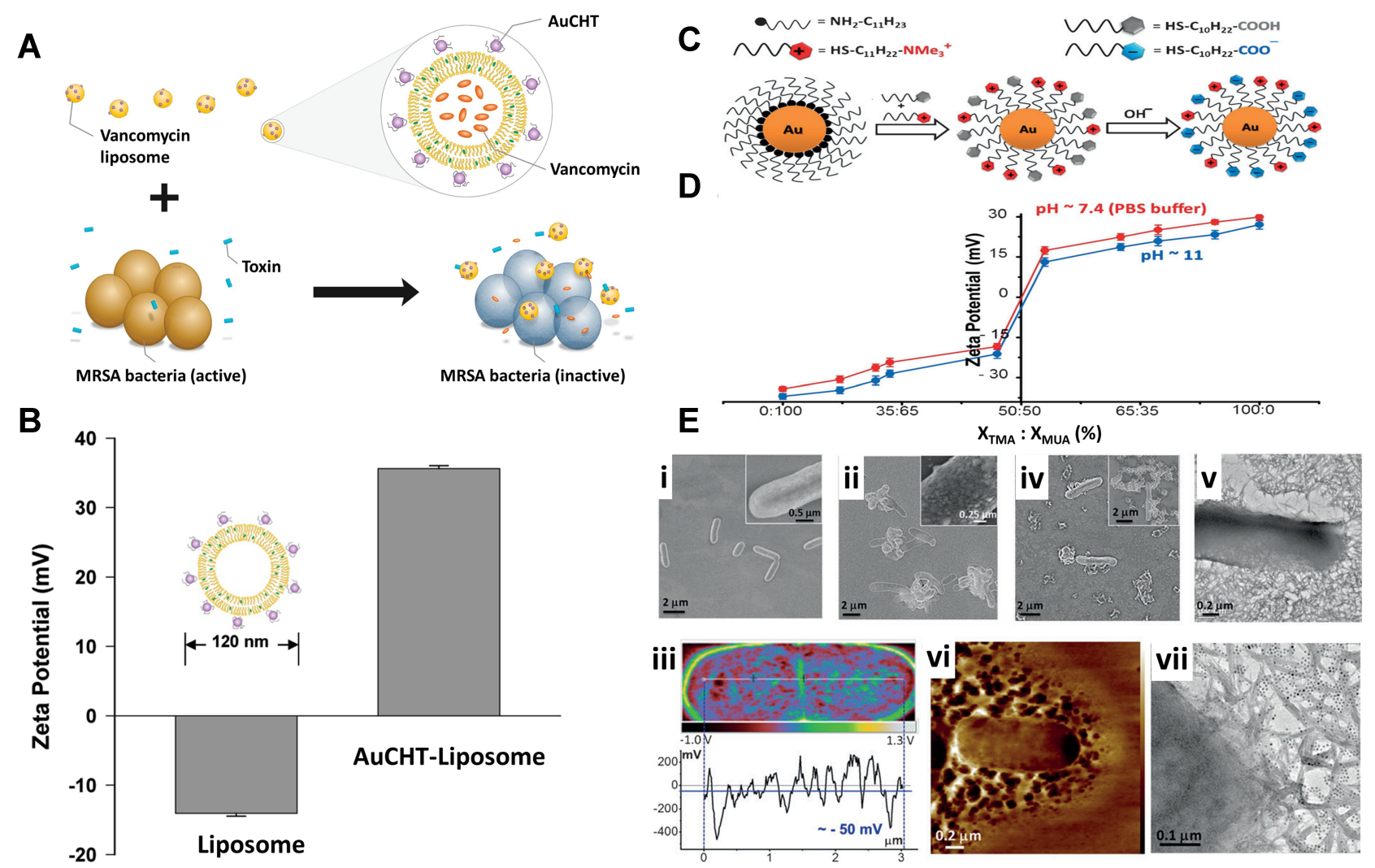

Figure 12 (A) Schematic principle of bacterial toxin-triggered antibiotic release from gold nanoparticle stabilized liposomes to treat toxin-secreting bacteria. Vancomycinloaded liposomes are protected by absorbing chitosan-coated gold nanoparticles (AuCHT) onto their surface to prevent them from fusing with one another or with bacterial membranes. Once the AuCHT-stabilized liposomes (AuCHT-liposome) encounter bacterial toxins, the toxins will form pores in the liposome membranes and thus release the encapsulated antibiotics, which subsequently kill or inhibit the growth of the bacteria that secrete the toxins. (B) The surface $\zeta$ potential (mV) of bare liposome (without $\mathrm{AuCHT}$ ) and AuCHT-liposome with a liposome/AuCHT molar ratio of I:300. Adapted with permission from Pornpattananangkul D, Zhang L, Olson S, et al. Bacterial toxin-triggered drug release from gold nanoparticle-stabilized liposomes for the treatment of bacterial infection. J Am Chem Soc. $201 \mathrm{I} ; \mathrm{I33}(\mathrm{II}): 4 \mathrm{I32}-4 \mathrm{I39}$. Copyright (201I) American Chemical Society. ${ }^{142}$ (C) Illustration of the synthesis of mixed-charge TMA/MUA nanoparticles. The relative compositions of these thiols in solution used for NP functionalization and on the resulting NPs are generally different, which is why the latter have to be determined independently by methods such as core etching followed by NMR. (D) Quantification of the NP charge polarities plotted against the composition of the mixed on-particle SAMs (composition expressed as XTMA: XMUA ratios as determined by core-etching/NMR analyses). The blue curve is for $\mathrm{pH} I \mathrm{I}$ and fully deprotonated MUAs; the red curve is for $\mathrm{pH} 7.4$ (PBS buffer) under which conditions a small fraction of the MUAs is protonated (and hence the curve shifts slightly upwards compared to the one for $\mathrm{pH}$ II). Error bars are based on three separate measurements. (E) Microscopic studies of bacteria treated with different types of mixed-charge NPs. Scanning electron microscopy (SEM) images of $E$. coli incubated with i) pure-MUA and ii) pure-TMA NPs. Inset in (B) shows TMA NPs adsorbing on the bacteria. For TEM images resolving the individual NPs. iii) Kelvin force microscopy (KFM) image of an $E$. coli bacterium illustrating its net negative surface potential of about $50 \mathrm{mV}$ (blue horizontal line). iv) SEM, v) TEM, and vi) AFM images of $E$. coli after incubation with cTMA:cMUA=80:20 AuNPs evidencing the rupture of the bacterial cell wall. vii) TEM image showing cTMA:cMUA=80:20 AuNPs (small dark dots) associated with the intracellular material leaked from the bacterium upon lysis. Adapted from Angewandte Chemie International Edition, Vol 55/ Issue 30, Pillai PP, Kowalczyk B, KandereGrzybowska K, Borkowska M, Grzybowski BA, Engineering gram selectivity of mixed-charge gold nanoparticles by tuning the balance of surface charges, Pages No.86I086I4, Copyright (2016), with permission from John Wiley and Sons. (c) 2016 WILEY-VCH Verlag GmbH \& Co. KGaA, Weinheim. ${ }^{143}$

more genes of drug resistance. Qiu et al suggested that it is because $\mathrm{Al}_{2} \mathrm{O}_{3}$-NMs cause oxidative destruction to the bacterial cell membrane and $\mathrm{Al}_{2} \mathrm{O}_{3}$-NM causes increased gene expression that endorses conjugation, and the lower manifestation of genes preventing conjugation. ${ }^{87}$

\section{Graphene-Based Nanomaterials (GPN-NMs)}

Graphene (GPN) is a carbon atom single layer sheet and emerging as broad-spectrum antimicrobial nanomaterial having significant action against bacteria, plant pathogens and fungi. Likewise, as compared to carbon nanotubes, GPN shows acceptable effect on mammalian cells. ${ }^{149}$ Generally, the antibacterial stuff of GPN involves physical and chemical properties. Physical injuries include direct contact of its sharp edges with bacterial membranes and destructive extraction of lipid molecules. These damages also include mechanisms of wrapping and photo-thermal ablation. Physical damage of bacterial membranes by sharp edges is a vital mechanism of the antibacterial activity of GPN. On the other hand, the chemical damage of bacteria is triggered by oxidative stress with ROS production and transfer of charge. Additionally, GPN is being used as supporting tool in dispersing and stabilizing different NMs like metals, metal oxides, and polymers, with great antibacterial competence because of synergistic outcome. ${ }^{150}$ 
The antibacterial action of graphene oxide (GPN-O) and reduced graphene oxide (rGPN-O) was firstly reported by Fan and Huang. ${ }^{151}$ The growth of $E$. coli is efficiently restricted by these NMs and confirmed by scanning electron microscopy (SEM). The bactericidal ability of graphene nano-walls placed on stainless steel was examined by Akhavan et al. ${ }^{152}$ They reported that direct contact of the sharp edges of GPN nano-walls with membranes of the bacteria causes inactivation of the bacteria. The bacterial membrane is ruptured by GPN nano-sheets resulting in the discharge of useful enzymes like $\beta$-D-galactosidase and electrolytes, finally death of the bacteria. The density of GPN edges is considered as main factor for optimum antibacterial property of GPN nano-sheets. The sharp edges have the ability to form the pores by cutting the bacterial cell membrane that consequently lead to osmotic imbalance and death of the bacteria. Other mechanisms include destructive extraction of phospholipid and microorganisms trapping. ${ }^{153}$

\section{Multiple Antibiotics Loading}

More than one antibiotics may be packed into the same NM to reduce the chances of resistance because bacteria would need more real-time mutation of genes to develop resistance against drugs. ${ }^{154}$ Furthermore, the incorporation of several drugs in the same NM can lead to better efficacy, greater antimicrobial ability, and can feasibly overwhelm the existing drug resistance methods in microorganisms compared to the sole drug. For instance, vancomycin loaded in chitosanNMs are active against VRSA, ${ }^{155}$ while vancomycin coated Au-NM has been observed to be active against E. coli and VRE with a 64-fold greater response in comparison to sole vancomycin. ${ }^{139}$ Ciprofloxacin coated Au-NM also showed augmented action against VRE. ${ }^{156}$

Benzoyl peroxide (BPO) loading into NMs of chitosan alginate (CHT-ALG-NMs) creates resistance unlikely system due to potential antibacterial effect of BPO and CHT. $\mathrm{BPO}$ causes oxidative pressure in microbial cells to induce bactericidal activity. ${ }^{157}$ CHT-ALG-NMs having BPO showed a higher potency against Propionibacterium acne (P. acne) compared to sole BPO and CHT-ALG-NMs, and no resistance of $P$. acnes is being reported yet.

Researchers reported that CHT loaded Ag-NMs (CHT@Ag-NMs) have the potential to inhibit the growth of $P$. aeruginosa, MRSA, A. baumannii and Proteus mirabilis. The antimicrobial action of these NMs was significant to these strains as compared to sole CHT and AgNMs. It was suggested that the synergistic outcome is attributable to the increased penetrability of CHT to the microbial cells, which make an easy entry for the Ag-NMs into the cells to induce stronger bactericidal action. ${ }^{158}$ Similarly, multiple metals can also be loaded into a single NM. The investigators found that $\mathrm{NM}$ of $\mathrm{TiO}_{2}$ and $\mathrm{Ag}$ $\left(\mathrm{TiO}_{2}-\mathrm{Ag}-\mathrm{NM}\right)$ are more effective against species of Aspergillus and C. albicans as compared to sole Ag-NM. When these NMs are exposed to visible light, higher antimicrobial and antiviral action have been seen than sole $\mathrm{TiO}_{2}$-NMPs. ${ }^{20}$

\section{NMs Role to Overcome the Decreased Drug Uptake and Increased Efflux}

Many NMs, especially dendrimers and liposomes, can combat resistance mechanisms including reduced uptake and increase in drug outflow from the cell. A liposome is a spherical vesicle with the wall consisting of one or more lipid bilayers. Each bilayer comprises phosphatidylcholine, amphipathic lipid, and cholesterol to rise the stiffness of the membranes. ${ }^{159}$ The lipid bilayer having an antimicrobial agent can easily enter the bacterial semi-permeable membrane and simultaneously deliver a large amount of the drug in the cytoplasm. Consequently, the liposomes dodge the mechanism of resistance of reduced drug uptake. Liposomes act as a quicker vehicle of the drugs with increased cytoplasm concentration. ${ }^{160}$ This drug concentration is sufficiently higher to saturate transmembrane pumps catalyzing an increase in drug outflow from the microbial cell. Hence, an increased outflow of drugs can be overcome by liposomes. ${ }^{161}$ With the inclusion of drugs in liposomes, this drug acquires a greater and faster antimicrobial activity, which leads to the death of microbes before there may be mutations that cause resistance to liposomes. ${ }^{162}$

Researchers reported that the minimum bactericidal concentration (MBC) of oleic acid (OA) loaded liposomes (OA-liposomes) is 12 times lesser against MRSA as compared to sole OA. Moreover, MRSA disease induced in mouse model, the antibacterial activity of OA-liposomes formulation was 500 times better than sole liposomes with the eradication of most bacterial cells within $48 \mathrm{~h}^{163}$ Polymixin-B loaded liposomes have amplified the antibacterial action against drug-resistant $P$. aeruginosa. Furthermore, these have been shown to cause lipid deformation on $P$. aeruginosa membrane indicating that liposomes and bacterial plasma membranes are fused. ${ }^{164}$ Likewise, aminoglycoside and vancomycin loaded liposomes also showed significant microbicide action to drug-resistant $P$. aeruginosa and MRSA membrane. ${ }^{165}$ 
Dendrimers are polymers with extensive branches about the central unit which offers a large proportion of surface area/volume. ${ }^{166}$ The surface of dendrimers have a large number of quaternary ammonium compounds (positive charge) linked to bacterial membranes (negative charge) and increases the penetrability of the membrane. It permits other dendrimers to invade the bacteria, therefore devastating the resistance method that is responsible for decreased drug uptake. It results in the release of contents of cytoplasmic from the cell and abolishes the microbial cells membrane. Due to these mechanisms, dendrimers loaded with quaternary ammonium compounds have higher antibacterial action than the sole antibiotics. ${ }^{167,168}$

\section{NMs Role in Biofilm Inhibition}

Some NMs try to combat microbial resistance by preventing the formation of biofilms. ${ }^{54}$ Hetrick et al reported that silicon dioxide $\mathrm{NMs}\left(\mathrm{SiO}_{2}-\mathrm{NMs}\right)$ kill those bacterial organisms which had biofilm already like $S$. aureus, E. coli, P. aeruginosa, C. albicans, and S. epidermidis. ${ }^{169}$ Similarly, Ag-NMs prevent the development of biofilms and it is possible that new bacterial cells are being stopped from the colonized system or existing biofilm surfaces. ${ }^{88}$ Roe et al presented Ag-NMs hinder the production of biofilms in S. aureus plastic catheters, coagulase-negative C. albicans, staphylococcal species, E. coli, Enterococcus, and P. aeruginosa. ${ }^{170} \mathrm{NMs}$ having a silver ring, magnetic core and a binder cap revealed that they prominently remove bacteria formed biofilms. ${ }^{171}$

There are other metallic NMs also which show antibiofilm activity. As coating glass surface of $\mathrm{ZnO}-\mathrm{NM}$ produces ROS and preventing biofilms. ${ }^{17}$ Another study states that $\mathrm{TiO}_{2}$-NMs internal thin-film composites disrupt the $E$. coli plasma membrane, thus inhibiting the adherence of $E$. coli to thin-film composites and reduces the speed of biofilm formation. Photo-activated Au-NM with methylene blue prevented biofilm formation against C. albicans. ${ }^{47} \mathrm{NMs}$ having Zero-valent Bi (Zero-valant Bi-NMs) were shown antibacterial and $100 \%$ of the biofilm formation was obtained by Streptococcus mutans. ${ }^{65}$ Qu's group presented enhanced anti-biofilm activity can be achieved by depositing metallic NMs on semiconductors. ${ }^{172}$

MgF2 hinders biofilm production by $S$. aureus and $E$. coli through restraining the bacterial cell binding to the surface. Hindrance to biofilm formation in $\mathrm{MgF}_{2}$ coated catheters in urine, plasma, and growth media are included in it. It is quite significant in the catheter infections caused by two bacterial species: E.coli and S. aureus. Formation of biofilm on the surface of the glass can also be hindered by coating the glass surfaces with $\mathrm{MgF}_{2}-\mathrm{NMs} \mathrm{MgF}_{2}-\mathrm{NMs}$ have a higher surface area to volume ratio which plays a major part in anti-biofilm characteristics. ${ }^{130,173}$

Superparamagnetic iron oxide-NMs (SPIO-NMs) like magnetic NMs utilize external magnetic fields to eradicate the bacterial biofilm. ${ }^{174} \mathrm{Ag}$ and $\mathrm{Au}$ coated SPIO-NMs have revealed the greatest anti-biofilm action against any kind of bacteria. ${ }^{175}$ Anghel et al performed an in-vitro experiment and observed that biofilm development and colonization in $C$. albicans is restrained by magnetite $\left(\mathrm{Fe}_{3} \mathrm{O}_{4}\right)$ coating textile dressings comparative to uncoated dressings. ${ }^{176}$ Chifiriuc et al studied that $\mathrm{Fe}_{3} \mathrm{O}_{4}$-NMs laminated with Rosmarinus officinalis essential oil showed a strong preventive effect of biofilm formation produced by Candida tropicalis and C. albicans. ${ }^{177,178}$ Biofilms produced by $S$. aureus and $S$. epidermidis are inhibited by cationic liposomes having benzylpenicillin and vancomycin, respectively. ${ }^{179}$

\section{NMs Combating Intracellular Bacteria}

Liposomes containing NMs are so minute that intracellular microbe containing host phagocyte can engulf them. Inside the host cell, NMs release drug to overcome the microbe present in the cell and antimicrobial drug is released by these NMs in the infected host. ${ }^{160}$ Intracellular microbe not stay alive before developing resistance by high local dose at the infectious area. On the other hand, the total low dose decreases the possibility of developing resistance by the bacteria present outside the infected site. ${ }^{180}$

NMs can fight against intracellular microbes in alveolar macrophages. Chlamydophila pneumoniae, M. tuberculosis, L. monocytogenes, and Legionella pneumophila are the microbes, which phagocytose and start proliferating inside the alveolar macrophages. When these microbes live in the host cell they are protected from several antibiotics. $^{20}$ Alveolar macrophages become targeted after attachment of drug-loaded NM to mannose, resulting in expression of mannose surface receptors. Selectivity for alveolar macrophages is observed when mannose is conjugated with ciprofloxacin loaded liposomes, is administered through the pulmonary route. Comparative to type II pneumocytes, liposomes conjugated with mannose lead to elevated antimicrobial drug concentration in the alveolar macrophages. ${ }^{181}$ It is hard to utilize NMs against infections inside the cell which are not the fragment of the mononuclear phagocyte system as non-mononuclear phagocyte system is unlikely to endocytose the NMs. A 
proposal to solve the difficulty is the utilization of stealth liposomes that has the potential to enter the MPS cells. ${ }^{182}$

\section{NMs Targeting Antimicrobials at the Infected Site}

Lastly, NMs target antimicrobials at the infectious area, consequently more drugs can reach the target area and overwhelming the resistance methods. ${ }^{19,66}$ Similar to the NMs targeting intracellular bacteria, NMs targeting infectious site may release a high amount of antimicrobials at infectious area keeping the total drug dose administered low. Intracellular microbe not survived before developing resistance by high local dose at the infectious area. On the other hand, the possibility of developing resistance by the bacteria present outside the infected site is lowered by the total low dose. ${ }^{183}$

Two ways of NMs targeted at site of infection are either passively or actively. Passively targeted NMs specifically go through extravasation at an infected area, where inflammation causes higher penetrability of the blood vessel. Actively targeted NMs have ligands like antibodies, which attach to receptors, ie, antigens at the infected area. Stimuli like low $\mathrm{pH}$ and ROS at the infected area may activate the antimicrobial action of NMs. To target NMs drug release to the infected area, radiofrequency and magnetic control regulate the drug release. ${ }^{22,140,184}$

Zhang's group have reviewed the concept of local antibiotic delivery based on nanoparticles. They illustrate the scheme of drug encapsulated inhalable materials for drug delivery to lungs, the SEM materials synthesized from leucine and mannitol through a method of spray drying and a high magnification image, respectively. They presented the fluorescence images of lungs from untreated rat and rat after intrapulmonary delivery of fluorescein-labelled nanomaterials (Figure 13A-E). An illustration of nanomaterial-hydrogel (NM-gel) system with tissue adhesive stuffs for local antimicrobial drug delivery. Dopamine meth acrylamide, abbreviated as DMA, having a functional group of catechol had coupled into gel-matrix for adhesion purpose. NM-gel tried for adhesion underflow on shaved mouse skin, HEK 293T cell monolayer, and E. coli film. In addition, bacteria gets treatment with PBS, blank gel, free drug (ciprofloxacin), drug encapsulated NMs, and drug encapsulated NMgel to give comparable results. (Figure $13 \mathrm{~F}-\mathrm{H}$ )

To cure pulmonary infections, silver carbene complexes (SCCs) in biodegradable NMs are targeted at lungs. SCCs present in biodegradable NMs are very minute so these may aggregate in the lungs after nebulizing. Adverse effects are very limited because, after their delivery inside the lungs, they regulate the effective therapeutic amount of SCCs only at the infected area. One of the examples is SCC's comprising L-Tyrosine polyphosphate NMs (LTP-NMs). ${ }^{104}$ In vitro, antimicrobial action against $C$. albicans, B. cepacia, $P$. aeruginosa, MRSA, $K$. pneumoniae, and multidrug-resis$\operatorname{tant} A$. baumannii (MRAB) is shown by SCCs loaded into LTP-NMs and free SCCs. ${ }^{18}$ Hindi et al studied that two inhaled doses administered about 72 hours of SCCs comprising LTP-NMs lower bacterial load in the lung, minimize bacteremia, and high survival by $25 \%$ in mouse models with P. aeruginosa pneumoniae. The method of NMs activity had observed to be a steady continuous liberation of intact SCCs, following the release from carbene of free silver ion that had an action against microbes in lungs at infected area. ${ }^{185}$

\section{Summary and Perspectives}

Antibiotic resistance (ABR) has become a global threat due to lack of new antibacterial agents and evolving resistance of MDR bacteria. Therefore, promptly intensifying danger demands novel approaches for the treatment in combatting resistant strains. Here, firstly we highlighted several schemes of bacteria developing the resistance against antibiotics. These resistance mechanisms include higher efflux and less drug uptake, expressing resistance gene, modification of antibiotics, antibiotics competitive inhibition, antibiotic tolerance, biofilms and swarming. The intrinsic talent of bacteria helps to change quickly by DNA transfer, ie, horizontal gene transfer, and mutations to overwhelm the antibiotic risks. Secondly antibacterial effect of NMs along with carrier for antimicrobials. NMs use to overcome the resistance pattern in bacteria is increasing with the passage of time. Numerous NMs apply multiple mechanisms like chitosan-NMs, metallic/metallic oxide NMs, etc., to prevent the progress of resistance by microbes. Synergistic antimicrobial action attained by loading antibiotic drugs into antibacterial NMs minimized the ABR.

The significant possible action of antibacterial NMs to combat infections in humans is accelerating and concerning the almost whole body organs (Figure 14). There is no available clinical nano-preparation for a vaccine at present that could be used to treat pandemic healthcare infections. ${ }^{186}$ Even though some antimicrobial NMs undergo clinical trials, but none of them has proceeded next to Phase-III period. ${ }^{187}$ 
A

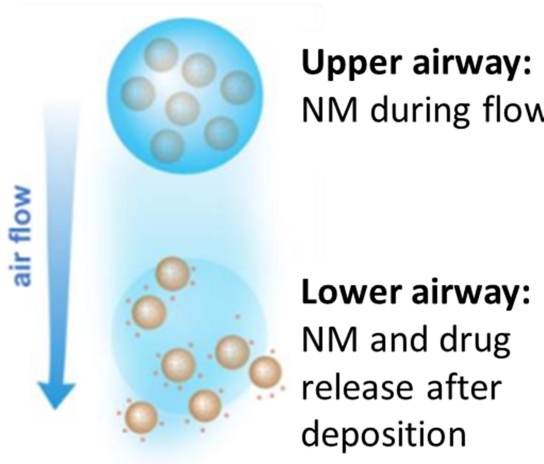

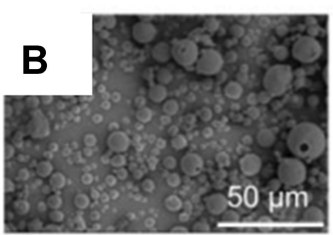
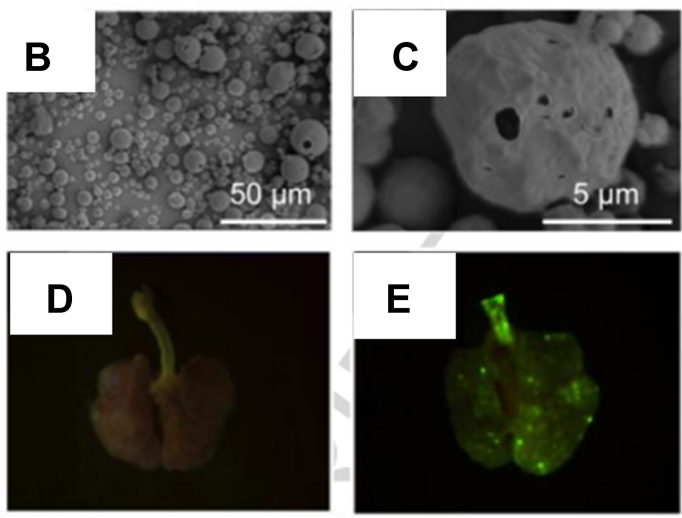

F

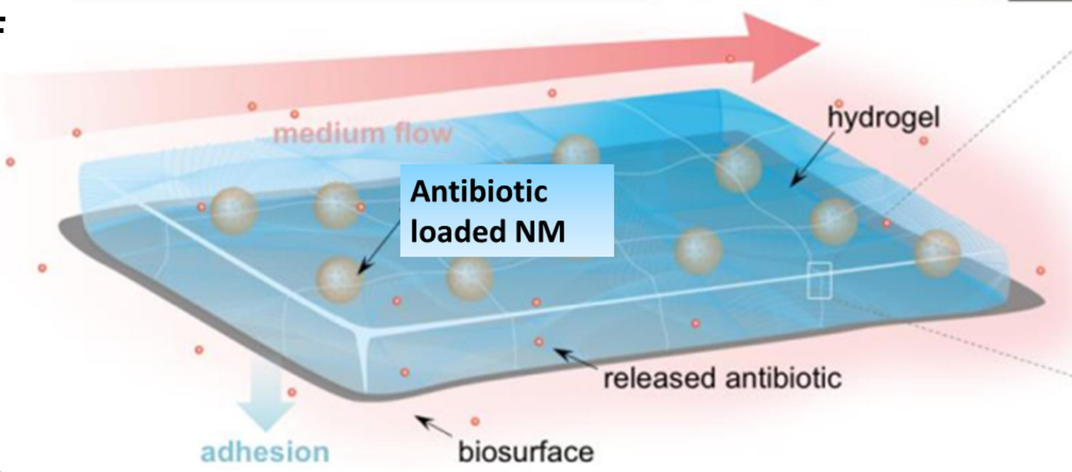

\section{G} Bacterial film

HEK 293T cell monolayer

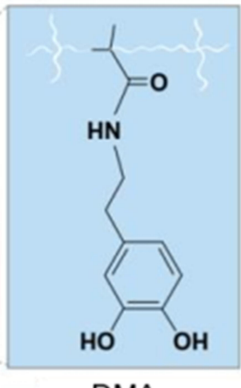

DMA

(adhesive moiety)

Mouse skin
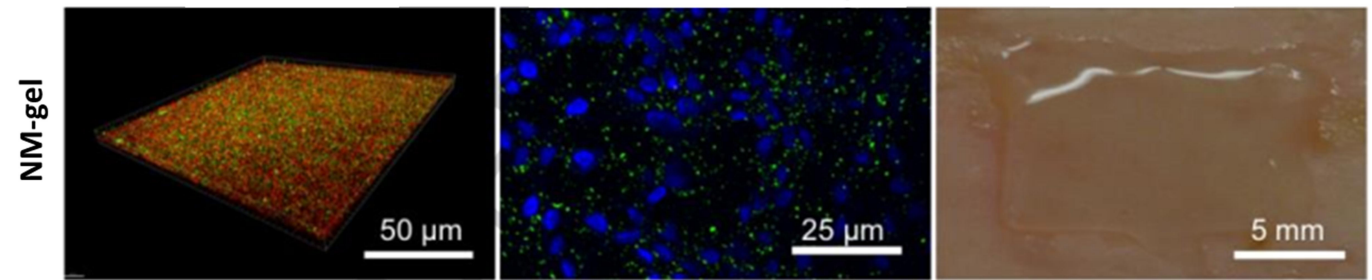

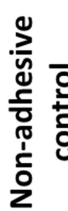
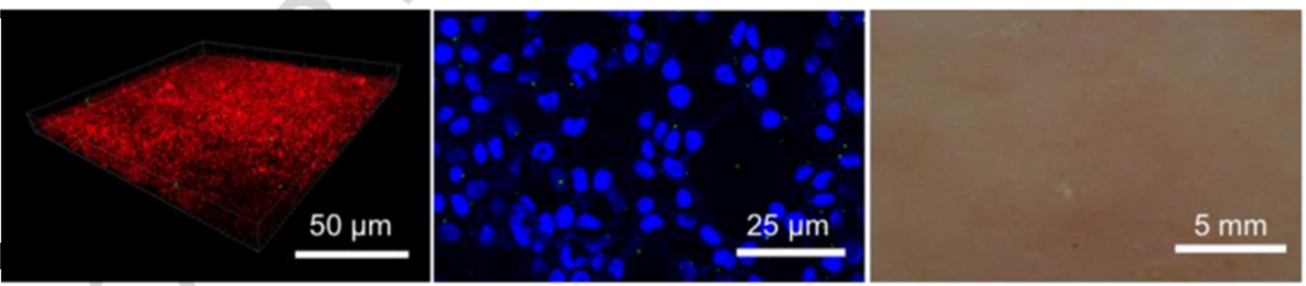

H

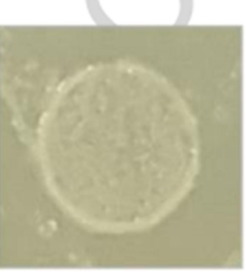

PBS

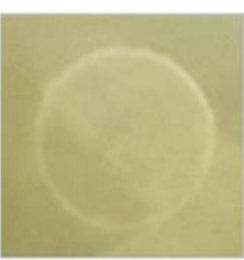

Blank gel

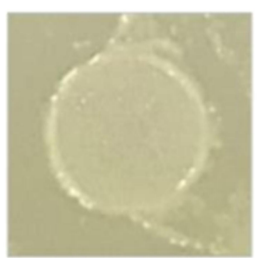

Free drug

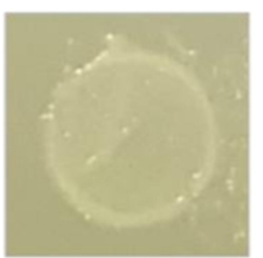

NMs only

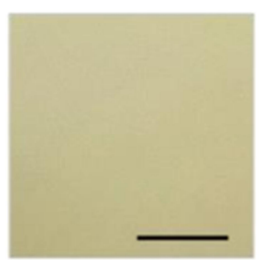

NM-gel

Figure 13 (A) Schematic illustration of inhalable particles as carriers for delivery of drug loaded nanoparticles to the deep lung. (B) Scanning microscopic images of microparticles made from mannitol and leucine using a spray-drying process. The microparticles were loaded with nanoparticles made from glyceryl monostearate and soybean phosphatidylcholine with a double emulsion process. (C) A zoomed-in image of (B). (D) Fluorescence images of lungs from untreated rat (E) and rat after intrapulmonary delivery of microparticles fluorescein-labeled nanoparticles. (F) Schematic illustration of a nanoparticle-hydrogel hybrid (NP-gel) system with tissue adhesive properties for localized antibiotic delivery under flow conditions. In this design, dopamine methacrylamide (DMA) containing catechol functional group was conjugated into gel matrix for adhesion. (G) NP-gel was tested for adhesion under a flow (shear stress $=3.2 \mathrm{~Pa}$ ) on E. coli bacterial film (green: nanoparticles in the gel; bacteria: red), HEK 293T cell monolayer (blue: cell nuclei; green: nanoparticles in the gel), and shaved mouse skin. (H) E. coli biofilm formation when the bacteria were treated with PBS, blank gel (gel without nanoparticles or ciprofloxacin), free ciprofloxacin, ciprofloxacin loaded nanoparticles (without hydrogel), and ciprofloxacin-loaded NP-gel (scale bar $=5 \mathrm{~mm}$ ). Reprinted from Advanced Drug Delivery Reviews, Vol I27, Gao W, Chen Y, Zhang Y, Zhang Q, Zhang L, Nanoparticle-based local antimicrobial drug delivery, Pages No.46-57, Copyright (2018), with permission from Elsevier. ${ }^{184}$ 
However, different approaches are handy to modify the pharmacological action of NMs leading to the introduction of new characteristics against existing treatments. For example, the use of multiple NMs to give synergistic antimicrobial effect. ${ }^{188}$ Similarly, surface modification improves the features (like hydrophilicity and avoid clumping) and pharmacological action of NMs (Figure 15A). It is observed that pharmacological activity and cytotoxicity are being affected directly by physio-chemical features (morphology, composition, size, charge, etc.) of NMs, ${ }^{189,190}$ and different materials like inorganic or organic are used to modify their surfaces. For instance, polymer and silane mediators used for coating NMs increase their hydrophilicity character. NMs surface coating will alter the interfacial association with bacterial and human cells, as a result, it affects the level of antimicrobial action and toxicity.

In addition to above-said approaches, green chemistry may play a vital role to enhance the biocompatibility of NMs used for bio-applications, ie, tissue rejuvenation and cellular therapies (Figure 15B). NMs synthesized by biomolecules produce more biocompatible NMs as compared to traditional synthesis strategies. Such as green synthesis of metallic NMs with biopolymer consequences in the development of polymer-coated NMs, having the capability of more compelling regarding antibacterial action and less toxic. ${ }^{191}$ There are two ways of biopolymers attachment to NMs, either on the surface or as a matrix to produce nanocomposite (NCs). NCs having swelling

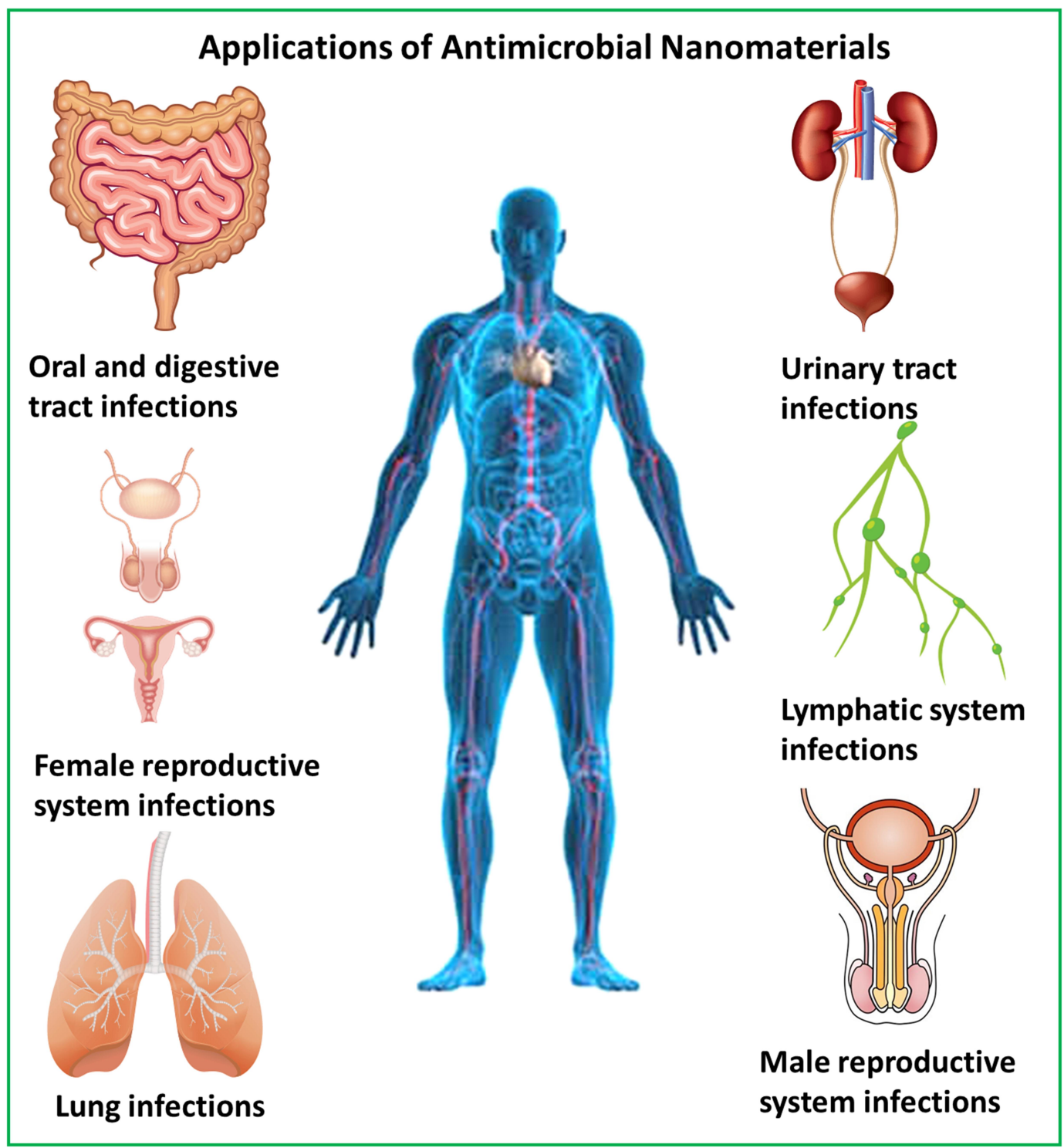

Figure 14 Antimicrobial materials potential to combat different infections in several organs of the human body. 


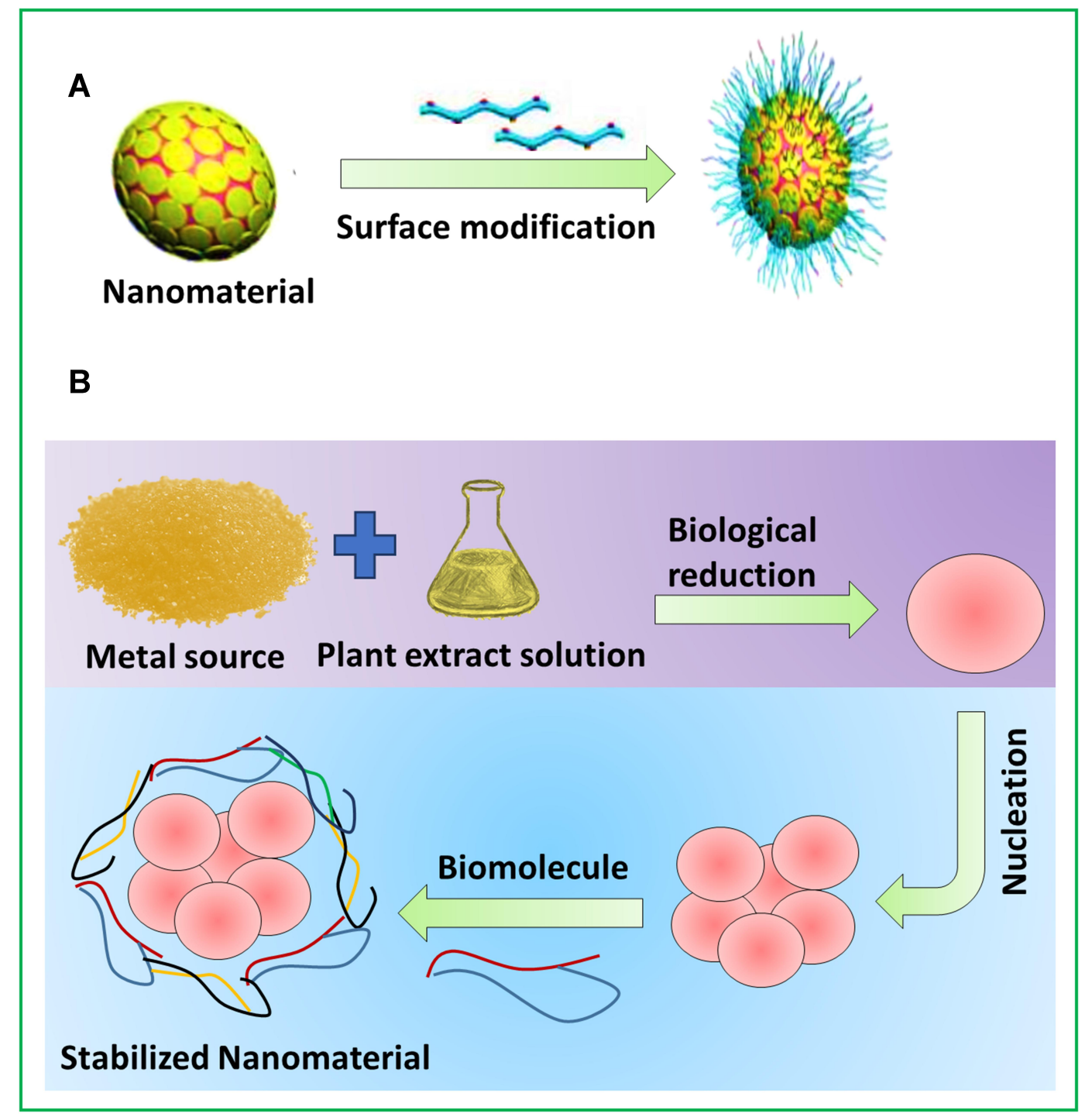

Figure 15 Methods to improve the biological action of metal nanomaterials. (A) Nanomaterials surface modification by biological substances. (B) Green synthesis of metal nanomaterials.

property are anticipated to treat wound infections, as better hydration is necessary for a speedy recovery from wound infections. ${ }^{192}$

Nevertheless, biopolymers are normally brittle and contain low resistance and heat stability for sustained processes.${ }^{193}$ There are few problems to use biopolymers in comparison to traditional non-biodegradable NMs. It includes barrier properties like increased-water penetrability, insufficient mechanical strength, and particularly when NCs are being applied as antimicrobial packing constituents. ${ }^{194}$ It is also of great importance that NMs increased quantity will affect the biopolymer character and accordingly the antibacterial property. For instance, a high concentration of metallic ions boosts the chitosan crystallinity and decreases the bacterial inhibition zone. These above-said issues must be resolved before we hope for clinical antimicrobial applications of NMs comes in reality.

\section{Disclosure}

The authors report no competing interests in this work.

\section{References}

1. Fischbach MA, Walsh CT. Antibiotics for emerging pathogens. Science. 2009;325(5944):1089-1093. doi:10.1126/science. 1176667

2. Linares JF, Gustafsson I, Baquero F, Martinez JL. Antibiotics as intermicrobial signaling agents instead of weapons. Proc Natl Acad Sci. 2006;103(51):19484-19489. doi:10.1073/pnas.0608949103

3. Peschel A, Sahl H-G. The co-evolution of host cationic antimicrobial peptides and microbial resistance. Nat Rev Microbiol. 2006;4(7):529536. doi:10.1038/nrmicro1441 
4. Initiative AR, Initiative PAAR. Detect and Protect Against Antibiotic Resistance.

5. Willyard C. The drug-resistant bacteria that pose the greatest health threats. Nat News. 2017;543(7643):15. doi:10.1038/ nature.2017.21550

6. Prestinaci F, Pezzotti P, Pantosti A. Antimicrobial resistance: a global multifaceted phenomenon. Pathogens Glob Health 2015;109(7):309-318. doi:10.1179/2047773215Y.0000000030

7. Laxminarayan R, Duse A, Wattal C, et al. Antibiotic resistancethe need for global solutions. Lancet Infect Dis. 2013;13 (12):1057-1098. doi:10.1016/S1473-3099(13)70318-9

8. Chambers HF. The changing epidemiology of Staphylococcus aureus? Emerg Infect Dis. 2001;7(2):178. doi:10.3201/ eid0702.010204

9. Lister PD, Wolter DJ, Hanson ND. Antibacterial-resistant pseudomonas aeruginosa: clinical impact and complex regulation of chromosomally encoded resistance mechanisms. Clin Microbiol Rev. 2009;22(4):582-610.

10. Perez F, Hujer AM, Hujer KM, Decker BK, Rather PN, Bonomo RA. Global challenge of multidrug-resistant acinetobacter baumannii. Antimicrob Agents Chemother. 2007;51(10):3471-3484. doi:10.1128/AAC.01464-06

11. Wright GD. Mechanisms of resistance to antibiotics. Curr Opin Chem Biol. 2003;7(5):563-569. doi:10.1016/j.cbpa.2003.08.004

12. Neu HC. The crisis in antibiotic resistance. Science. 1992;257 (5073):1064-1073. doi:10.1126/science.257.5073.1064

13. Berger-Bächi B. Expression of resistance to methicillin. Trends Microbiol. 1994;2(10):389-393. doi:10.1016/0966-842X(94)90617-3

14. Rolain JM, Parola P, Cornaglia G. New Delhi metallo-beta-lactamase (NDM-1): towards a new pandemia? Clin Microbiol Infect. 2010;16(12):1699-1701. doi:10.1111/j.1469-0691.2010.03385.x

15. Devaux I, Kremer K, Heersma H, Van Soolingen D. Clusters of multidrug-resistant mycobacterium tuberculosis cases, Europe Emerg Infect Dis. 2009;15(7):1052. doi:10.3201/eid1507.080994

16. Hajipour MJ, Fromm KM, Ashkarran AA, et al. Antibacterial properties of nanoparticles. Trends Biotechnol. 2012;30 (10):499-511. doi:10.1016/j.tibtech.2012.06.004

17. Schröfel A, Kratošová G, Šafařík I, Šafaříková M, Raška I, Shor LM. Applications of biosynthesized metallic nanoparticles-a review. Acta Biomater. 2014;10(10):4023-4042. doi:10.1016/j. actbio.2014.05.022

18. Zhang L, Pornpattananangkul D, Hu C-M, Huang C-M. Development of nanoparticles for antimicrobial drug delivery. Curr Med Chem. 2010;17(6):585-594. doi:10.2174/ 092986710790416290

19. Gupta A, Mumtaz S, Li CH, Hussain I, Rotello VM. Combatting antibiotic-resistant bacteria using nanomaterials. Chem Soc Rev. 2019;48(2):415-427. doi:10.1039/c7cs00748e.

20. Huh AJ, Kwon YJ. "Nanoantibiotics": a new paradigm for treating infectious diseases using nanomaterials in the antibiotics resistant era. $J$ Control Release. 2011;156(2):128-145. doi:10.1016/j.jconrel.2011.07.002

21. Miller KP, Wang L, Benicewicz BC, Decho AW. Inorganic nanoparticles engineered to attack bacteria. Chem Soc Rev. 2015;44 (21):7787-7807.

22. Blair JMA, Webber MA, Baylay AJ, Ogbolu DO, Piddock LJV. Molecular mechanisms of antibiotic resistance. Nat Rev Microbiol. 2015;13(1):42-51. doi:10.1038/nrmicro3380

23. Davies J, Davies D. Origins and evolution of antibiotic resistance. Microbiol Mol Biol Rev. 2010;74(3):417-433. doi:10.1128/ MMBR.00016-10

24. Jayaraman R. Antibiotic resistance: an overview of mechanisms and a paradigm shift. Curr Sci. 2009;1475-1484.

25. Livermore DM. Bacterial resistance: origins, epidemiology, and impact. Clin Infect Dis. 2003;36(Supplement_1):S11-S23. doi: $10.1086 / 344654$
26. Poole K. Mechanisms of bacterial biocide and antibiotic resistance. J Appl Microbiol. 2002;92(s1):55S-64S. doi:10.1046/ j.1365-2672.92.5s1.8.x

27. Caro RDC, Cannizzaro MV, Botti E, et al. Clindamycin versus clindamycin plus rifampicin in hidradenitis suppurativa treatment: clinical and ultrasound observations. $J \mathrm{Am}$ Acad Dermatol. 2019;80(5):1314-1321. doi:10.1016/j. jaad.2018.11.035

28. Quintiliani R. Using pharmacodynamic and pharmacokinetic concepts to optimize treatment of infectious diseases. Infect Med. 2004;21(5):219-232.

29. Bernier SP, Surette MG. Concentration-dependent activity of antibiotics in natural environments. Front Microbiol. 2013;4:20. doi:10.3389/fmicb.2013.00020

30. Wright GD. Molecular mechanisms of antibiotic resistance. Chem Commun. 2011;47(14):4055-4061. doi:10.1039/c0cc05111j

31. Nikaido H. Multidrug resistance in bacteria. Annu Rev Biochem. 2009;78(1):119-146. doi:10.1146/annurev.biochem.78.082907.1459 23

32. Du D, Wang-Kan X, Neuberger A, et al. Multidrug efflux pumps: structure, function and regulation. Nat Rev Microbiol. 2018;16(9):523-539. doi:10.1038/s41579-0180048-6

33. Vargiu AV, Nikaido H. Multidrug binding properties of the ACRB efflux pump characterized by molecular dynamics simulations. Proc Natl Acad Sci. 2012;109(50):20637-20642. doi:10.1073/ pnas. 1218348109

34. Siegel SD, Liu J, Ton-That H. Biogenesis of the gram-positive bacterial cell envelope. Curr Opin Microbiol. 2016;34:31-37. doi:10.1016/j.mib.2016.07.015

35. Appelbaum PC, Jacobs MR. Recently approved and investigational antibiotics for treatment of severe infections caused by gram-positive bacteria. Curr Opin Microbiol. 2005;8(5):510517. doi:10.1016/j.mib.2005.07.001

36. Deck DH, Winston LG. Sulfonamides, trimethoprim, quinolones. Basic Clin Pharmacol. 2012.

37. Povolo VR, Ackermann M. Disseminating antibiotic resistance during treatment. Science. 2019;364(6442):737-738. doi:10.1126/ science.aax 6620

38. Yamasaki S, Nikaido E, Nakashima R, et al. The crystal structure of multidrug-resistance regulator RAMR with multiple drugs. Nat Commun. 2013;4(1):1-7. doi:10.1038/ ncomms 3078

39. Moyá B, Beceiro A, Cabot G, et al. Pan- $\beta$-lactam resistance development in pseudomonas aeruginosa clinical strains: molecular mechanisms, penicillin-binding protein profiles, and binding affinities. Antimicrob Agents Chemother. 2012;56(9):4771-4778. doi:10.1128/AAC.00680-12

40. Chang S, Sievert DM, Hageman JC, et al. Infection with vancomycin-resistant staphylococcus aureus containing the vana resistance gene. $N$ Engl $J$ Med. 2003;348(14):1342-1347. doi:10.1056/NEJMoa025025

41. Achari A, Somers DO, Champness JN, Bryant PK, Rosemond J, Stammers DK. Crystal structure of the anti-bacterial sulfonamide drug target dihydropteroate synthase. Nat Struct Biol. 1997;4 (6):490-497. doi:10.1038/nsb0697-490

42. Zignol M, Cabibbe AM, Dean AS, et al. Genetic sequencing for surveillance of drug resistance in tuberculosis in highly endemic countries: a multi-country population-based surveillance study. Lancet Infect Dis. 2018;18(6):675-683. doi:10.1016/S1473-3099 (18)30073-2

43. Rodríguez-Martínez JM, Briales A, Velasco C, Conejo MC, Martínez-Martínez L, Pascual A. Mutational analysis of quinolone resistance in the plasmid-encoded pentapeptide repeat proteins QnrA, QnrB and QnrS. J Antimicrob Chemother. 2009;63(6):1128-1134. doi:10.1093/jac/dkp111 
44. Gatermann SG, Koschinski T, Friedrich S. Distribution and expression of macrolide resistance genes in coagulase-negative staphylococci. Clin Microbiol Infect. 2007;13(8):777-781. doi:10.1111/j.1469-0691.2007.01749.x

45. Gu B, Kelesidis T, Tsiodras S, Hindler J, Humphries RM. The emerging problem of linezolid-resistant staphylococcus. $J$ Antimicrob Chemother. 2013;68(1):4-11. doi:10.1093/jac/dks354

46. Bush K, Jacoby GA. Updated functional classification of $\beta$-lactamases. Antimicrob Agents Chemother. 2010;54(3):969-976. doi:10.1128/AAC.01009-09

47. Khan AU. Medicine at nanoscale: a new horizon. Int $J$ Nanomedicine. 2012;7:2997. doi:10.2147/IJN.S33238

48. Kumarasamy KK, Toleman MA, Walsh TR, et al. Emergence of a new antibiotic resistance mechanism in India, Pakistan, and the UK: a molecular, biological, and epidemiological study. Lancet Infect Dis. 2010;10(9):597-602. doi:10.1016/S1473-3099(10) 70143-2

49. Wright GD. Bacterial resistance to antibiotics: enzymatic degradation and modification. Adv Drug Deliv Rev. 2005;57(10):14511470. doi:10.1016/j.addr.2005.04.002

50. Robicsek A, Strahilevitz J, Jacoby GA, et al. Fluoroquinolonemodifying enzyme: a new adaptation of a common aminoglycoside acetyltransferase. Nat Med. 2006;12(1):83-88. doi:10.1038/ $\mathrm{nm} 1347$

51. Ponce CA, Chabé M, George C, et al. High prevalence of pneumocystis jirovecii dihydropteroate synthase gene mutations in patients with a first episode of pneumocystis pneumonia in Santiago, Chile, and clinical response to trimethoprim-sulfamethoxazole therapy. Antimicrob Agents Chemother. 2017;61(2): e01290-16. doi:10.1128/AAC.01290-16

52. Liu C, Bayer A, Cosgrove SE, et al. Clinical practice guidelines by the Infectious Diseases Society of America for the treatment of methicillin-resistant staphylococcus aureus infections in adults and children. Clin Infect Dis. 2011;52(3):e18-e55.

53. Helaine S, Kugelberg E. Bacterial persisters: formation, eradication, and experimental systems. Trends Microbiol. 2014;22 (7):417-424. doi:10.1016/j.tim.2014.03.008

54. Conlon BP, Nakayasu ES, Fleck LE, et al. Activated ClpP kills persisters and eradicates a chronic biofilm infection. Nature. 2013;503(7476):365-370. doi:10.1038/nature12790

55. Arciola CR, Campoccia D, Montanaro L. Implant infections: adhesion, biofilm formation and immune evasion. Nat Rev Microbiol. 2018;16(7):397. doi:10.1038/s41579-018-0019-y

56. Stewart PS, Costerton JW. Antibiotic resistance of bacteria in biofilms. Lancet. 2001;358(9276):135-138. doi:10.1016/S01406736(01)05321-1

57. Hoffman LR, D’Argenio DA, MacCoss MJ, Zhang Z, Jones RA, Miller SI. Aminoglycoside antibiotics induce bacterial biofilm formation. Nature. 2005;436(7054):1171-1175. doi:10.1038/ nature 03912

58. Gunn JS, Bakaletz LO, Wozniak DJ. What's on the outside matters: the role of the extracellular polymeric substance of gram-negative biofilms in evading host immunity and as a target for therapeutic intervention. J Biol Chem. 2016;291(24):1253812546. doi:10.1074/jbc.R115.707547

59. Ferreira C, Pereira AM, Melo LF, Simões M. Advances in industrial biofilm control with micro-nanotechnology. Curr Res Technol Educ Top Appl Microbiol Microb Biotechnol. 2010;2:845-854.

60. Fulaz S, Vitale S, Quinn L, Casey E. Nanoparticle-biofilm interactions: the role of the EPS matrix. Trends Microbiol. 2019;27 (11):915-926. doi:10.1016/j.tim.2019.07.004

61. DeLeon S, Clinton A, Fowler H, Everett J, Horswill AR, Rumbaugh KP. Synergistic interactions of pseudomonas aeruginosa and staphylococcus aureus in an in vitro wound model. Infect Immun. 2014;82(11):4718-4728. doi:10.1128/IAI.02198-14
62. Kearns DB. A field guide to bacterial swarming motility. Nat Rev Microbiol. 2010;8(9):634-644. doi:10.1038/nrmicro2405

63. Lai S, Tremblay J, Déziel E. Swarming motility: a multicellular behaviour conferring antimicrobial resistance. Environ Microbiol. 2009;11(1):126-136. doi:10.1111/j.1462-2920.2008.01747.x

64. Pelgrift RY, Friedman AJ. Nanotechnology as a therapeutic tool to combat microbial resistance. Adv Drug Deliv Rev. 2013;65(1314):1803-1815. doi:10.1016/j.addr.2013.07.011

65. Liu Y, Shi L, Su L, et al. Nanotechnology-based antimicrobials and delivery systems for biofilm-infection control. Chem Soc Rev. 2019;48(2):428-446. doi:10.1039/C7CS00807D

66. Munir MU, Ihsan A, Sarwar Y, et al. Hollow mesoporous hydroxyapatite nanostructures; smart nanocarriers with high drug loading and controlled releasing features. Int J Pharm. 2018;544 (1):112-120. doi:10.1016/j.ijpharm.2018.04.029.

67. Kaur A, Preet S, Kumar V, Kumar R, Kumar R. Synergetic effect of vancomycin loaded silver nanoparticles for enhanced antibacterial activity. Colloids Surf B Biointerfaces. 2019;176:62-69. doi:10.1016/j.colsurfb.2018.12.043

68. Pant J, Goudie MJ, Hopkins SP, Brisbois EJ, Handa H. Tunable nitric oxide release from s-nitroso-n-acetylpenicillamine via catalytic copper nanoparticles for biomedical applications. ACS Appl Mater Interfaces. 2017;9(18):15254-15264. doi:10.1021/ acsami.7b01408

69. Wang L, Hu C, Shao L. The-antimicrobial-activity-of-nanoparticles-present-situation. Int J Nanomedicine. 2017;12:1227-1249. doi:10.2147/IJN.S121956.

70. Nguyen T-K, Selvanayagam R, Ho KKK, et al. Co-delivery of nitric oxide and antibiotic using polymeric nanoparticles. Chem Sci. 2016;7(2):1016-1027. doi:10.1039/C5SC02769A

71. Dolanský J, Henke P, Malá Z, Žárská L, Kubát P, Mosinger J. Antibacterial nitric oxide-and singlet oxygen-releasing polystyrene nanoparticles responsive to light and temperature triggers. Nanoscale. 2018;10(5):2639-2648. doi:10.1039/C7NR08822A

72. Privett BJ, Broadnax AD, Bauman SJ, Riccio DA, Schoenfisch MH. Examination of bacterial resistance to exogenous nitric oxide. Nitric Oxide. 2012;26(3):169-173. doi:10.1016/j. niox.2012.02.002

73. Hall JR, Rouillard KR, Suchyta DJ, Brown MD, Ahonen MJR, Schoenfisch MH. Mode of nitric oxide delivery affects antibacterial action. ACS Biomater Sci Eng. 2019.

74. Schairer DO, Chouake JS, Nosanchuk JD, Friedman AJ. The potential of nitric oxide releasing therapies as antimicrobial agents. Virulence. 2012;3(3):271-279. doi:10.4161/viru.20328

75. Rosen J, Landriscina A, Nosanchuk JD. Nitric oxide-releasing nanoparticles as an antimicrobial therapeutic. In: Nanoscience in Dermatology. Elsevier; 2016;pp 127-134.

76. Mousavi SA, Ghotaslou R, Kordi S, et al. Antibacterial and antifungal effects of chitosan nanoparticles on tissue conditioners of complete dentures. Int J Biol Macromol. 2018;118:881-885. doi:10.1016/j.ijbiomac.2018.06.151

77. Yang J, Lu H, Li M, et al. Development of chitosan-sodium phytate nanoparticles as a potent antibacterial agent. Carbohydr Polym. 2017;178:311-321. doi:10.1016/j.carbpol.2017.09.053

78. Hosseinnejad M, Jafari SM. Evaluation of different factors affecting antimicrobial properties of chitosan. Int J Biol Macromol. 2016;85:467-475. doi:10.1016/j.ijbiomac.2016.01.022

79. Ma Z, Garrido-Maestu A, Jeong KC. Application, mode of action, and in vivo activity of chitosan and its micro-and nanoparticles as antimicrobial agents: a review. Carbohydr Polym. 2017;176:257265. doi:10.1016/j.carbpol.2017.08.082

80. Wassel MO, Khattab MA. Antibacterial activity against streptococcus mutans and inhibition of bacterial induced enamel demineralization of propolis, miswak, and chitosan nanoparticles based dental varnishes. $J$ Adv Res. 2017;8(4):387-392. doi:10.1016/j.jare.2017.05.006 
81. Shi Z, Neoh KG, Kang ET, Wang W. Antibacterial and mechanical properties of bone cement impregnated with chitosan nanoparticles. Biomaterials. 2006;27(11):2440-2449. doi:10.1016/j. biomaterials.2005.11.036

82. Wang JJ, Zeng ZW, Xiao RZ, et al. Recent advances of chitosan nanoparticles as drug carriers. Int J Nanomedicine. 2011;6:765. doi:10.2147/IJN.S25646

83. Chen F, Shi Z, Neoh KG, Kang ET. Antioxidant and antibacterial activities of eugenol and carvacrol-grafted chitosan nanoparticles. Biotechnol Bioeng. 2009;104(1):30-39. doi:10.1002/bit.22363

84. Marangon CA, Martins VCA, Ling MH, et al. Combination of rhamnolipid and chitosan in nanoparticles boosts their antimicrobial efficacy. ACS Appl Mater Interfaces. 2020;12(5):5488-5499. doi:10.1021/acsami.9b19253.

85. Wyszogrodzka G, Marszałek B, Gil B, Dorożyński P. Metalorganic frameworks: mechanisms of antibacterial action and potential applications. Drug Discov Today. 2016;21(6):10091018. doi:10.1016/j.drudis.2016.04.009

86. Luo Y, Hossain M, Wang C, et al. Targeted nanoparticles for enhanced $\mathrm{X}$-ray radiation killing of multidrug-resistant bacteria. Nanoscale. 2013;5(2):687-694. doi:10.1039/C2NR33154C

87. Qiu Z, Yu Y, Chen Z, et al. Nanoalumina promotes the horizontal transfer of multiresistance genes mediated by plasmids across genera. Proc Natl Acad Sci. 2012;109(13):4944-4949. doi:10.1073/pnas.1107254109

88. Ramalingam B, Parandhaman T, Das SK. Antibacterial effects of biosynthesized silver nanoparticles on surface ultrastructure and nanomechanical properties of gram-negative bacteria viz. escherichia coli and pseudomonas aeruginosa. ACS Appl Mater Interfaces. 2016;8(7):4963-4976. doi:10.1021/acsami.6b00161

89. Dakal TC, Kumar A, Majumdar RS, Yadav V. Mechanistic basis of antimicrobial actions of silver nanoparticles. Front Microbiol. 2016;7:1831. doi:10.3389/fmicb.2016.01831

90. Song Z, Wu Y, Wang H, Han H. Synergistic antibacterial effects of curcumin modified silver nanoparticles through ROS-mediated pathways. Mater Sci Eng C. 2019;99:255-263. doi:10.1016/j. msec.2018.12.053

91. Acharya D, Singha KM, Pandey P, Mohanta B, Rajkumari J, Singha LP. Shape dependent physical mutilation and lethal effects of silver nanoparticles on bacteria. Sci Rep. 2018;8(1):201. doi:10.1038/s41598-017-18590-6

92. Mahmoudi M, Serpooshan V. Silver-coated engineered magnetic nanoparticles are promising for the success in the fight against antibacterial resistance threat. ACS Nano. 2012;6(3):2656-2664. doi:10.1021/nn300042m

93. Brown AN, Smith K, Samuels TA, Lu J, Obare SO, Scott ME. Nanoparticles functionalized with ampicillin destroy multipleantibiotic-resistant isolates of pseudomonas aeruginosa and enterobacter aerogenes and methicillin-resistant staphylococcus aureus. Appl Environ Microbiol. 2012;78(8):2768-2774. doi:10.1128/AEM.06513-11

94. Cheon JY, Kim SJ, Rhee YH, Kwon OH, Park WH. Shapedependent antimicrobial activities of silver nanoparticles. Int $J$ Nanomedicine. 2019;14:2773. doi:10.2147/IJN.S196472

95. Hu Z, Zhang L, Zhong L, Zhou Y, Xue J, Li Y. Preparation of an antibacterial chitosan-coated biochar-nanosilver composite for drinking water purification. Carbohydr Polym. 2019;219:290297. doi:10.1016/j.carbpol.2019.05.017

96. Liu Z, Wang Y, Zu Y, et al. Synthesis of polyethylenimine (PEI) functionalized silver nanoparticles by a hydrothermal method and their antibacterial activity study. Mater Sci Eng C. 2014;42:3137. doi:10.1016/j.msec.2014.05.007

97. Zhao R, Lv M, Li Y, et al. Stable nanocomposite based on pegylated and silver nanoparticles loaded graphene oxide for long-term antibacterial activity. ACS Appl Mater Interfaces. 2017;9(18):15328-15341. doi:10.1021/acsami.7b03987
98. Durán N, Durán M, De Jesus MB, Seabra AB, Fávaro WJ, Nakazato G. Silver nanoparticles: a new view on mechanistic aspects on antimicrobial activity. Nanomed Nanotechnol. 2016;12(3):789-799. doi:10.1016/j.nano.2015.11.016

99. Wang L, Zhang T, Li P, et al. Use of synchrotron radiationanalytical techniques to reveal chemical origin of silver-nanoparticle cytotoxicity. ACS Nano. 2015;9(6):6532-6547.

100. Khorrami S, Zarrabi A, Khaleghi M, Danaei M, Mozafari MR. Selective cytotoxicity of green synthesized silver nanoparticles against the MCF-7 tumor cell line and their enhanced antioxidant and antimicrobial properties. Int J Nanomedicine. 2018;13:8013. doi:10.2147/IJN.S189295

101. Alavi M, Karimi N, Valadbeigi T. Antibacterial, antibiofilm, antiquorum sensing, antimotility, and antioxidant activities of green fabricated $\mathrm{Ag}, \mathrm{Cu}, \mathrm{TiO} 2, \mathrm{ZnO}$, and $\mathrm{Fe} 3 \mathrm{O} 4$ NPs via protoparmeliopsis muralis lichen aqueous extract against multi-drugresistant bacteria. ACS Biomater Sci Eng. 2019;5(9):4228-4243. doi:10.1021/acsbiomaterials.9b00274

102. Kim JS, Kuk E, Yu KN, et al. Antimicrobial effects of silver nanoparticles. Nanomed Nanotechnol. 2007;3(1):95-101. doi:10.1016/j.nano.2006.12.001

103. Wang Y, Ding X, Chen Y, et al. Antibiotic-loaded, silver coreembedded mesoporous silica nanovehicles as a synergistic antibacterial agent for the treatment of drug-resistant infections. Biomaterials. 2016;101:207-216. doi:10.1016/j.biomaterials.2016.06.004

104. Mottais A, Berchel M, Le Gall T, Sibiril Y. Antibacterial and transfection activities of nebulized formulations incorporating long n-alkyl chain silver n-heterocyclic carbene complexes. Int J Pharm. 2019;567:118500. doi:10.1016/j.ijpharm.2019.118500

105. Rai M, Deshmukh SD, Ingle AP, Gupta IR, Galdiero M, Galdiero S. The protective nanoshield against virus infection. Crit Rev Microbiol. 2016;42(1):46-56. doi:10.3109/1040841X.2013.879849

106. Sirelkhatim A, Mahmud S, Seeni A, et al. Review on zinc oxide nanoparticles: antibacterial activity and toxicity mechanism. Nano-Micro Lett. 2015;7(3):219-242. doi:10.1007/s40820-0150040-x

107. Mishra PK, Mishra H, Ekielski A, Talegaonkar S, Vaidya B. Zinc oxide nanoparticles: a promising nanomaterial for biomedical applications. Drug Discov Today. 2017;22(12):1825-1834. doi:10.1016/j.drudis.2017.08.006

108. Siddiqi KS, Ur Rahman A, Husen A. Properties of zinc oxide nanoparticles and their activity against microbes. Nanoscale Res Lett. 2018;13(1):1-13. doi:10.1186/s11671-018-2532-3

109. Król A, Pomastowski P, Rafińska K, Railean-Plugaru V, Buszewski B. Zinc oxide nanoparticles: synthesis, antiseptic activity and toxicity mechanism. Adv Colloid Interfac Sci. 2017;249:37-52. doi:10.1016/j.cis.2017.07.033

110. Kadiyala U, Turali-Emre ES, Bahng JH, Kotov NA, VanEpps JS. Unexpected insights into antibacterial activity of zinc oxide nanoparticles against methicillin resistant staphylococcus aureus (MRSA). Nanoscale. 2018;10(10):4927-4939. doi:10.1039/ C7NR08499D

111. Ramani M, Ponnusamy S, Muthamizhchelvan C. From zinc oxide nanoparticles to microflowers: a study of growth kinetics and biocidal activity. Mater Sci Eng C. 2012;32(8):2381-2389. doi:10.1016/j.msec.2012.07.011

112. Pati R, Mehta RK, Mohanty S, et al. Topical application of zinc oxide nanoparticles reduces bacterial skin infection in mice and exhibits antibacterial activity by inducing oxidative stress response and cell membrane disintegration in macrophages. Nanomed Nanotechnol. 2014;10(6):1195-1208. doi:10.1016/j. nano.2014.02.012

113. Meghana S, Kabra P, Chakraborty S, Padmavathy N. Understanding the pathway of antibacterial activity of copper oxide nanoparticles. RSC Adv. 2015;5(16):12293-12299. doi:10.1039/C4RA12163E 
114. Hassan MS, Amna T, Yang O-B, El-Newehy MH, Al-Deyab SS, Khil M-S. Smart copper oxide nanocrystals: synthesis, characterization, electrochemical and potent antibacterial activity. Colloids Surf B Biointerfaces. 2012;97:201-206. doi:10.1016/j. colsurfb.2012.04.032

115. Ananth A, Dharaneedharan S, Heo M-S, Mok YS. Copper oxide nanomaterials: synthesis, characterization and structure-specific antibacterial performance. Chem Eng J. 2015;262:179-188. doi:10.1016/j.cej.2014.09.083

116. Azam A, Ahmed AS, Oves M, Khan MS, Memic A. Size-dependent antimicrobial properties of $\mathrm{CuO}$ nanoparticles against grampositive and-negative bacterial strains. Int $J$ Nanomedicine. 2012;7:3527. doi:10.2147/IJN.S29020

117. Laha D, Pramanik A, Laskar A, Jana M, Pramanik P, Karmakar P. Shape-dependent bactericidal activity of copper oxide nanoparticle mediated by DNA and membrane damage. Mater Res Bull. 2014;59:185-191. doi:10.1016/j.materresbull.2014.06.024

118. Li M, Gao L, Schlaich C, et al. Construction of functional coatings with durable and broad-spectrum antibacterial potential based on mussel-inspired dendritic polyglycerol and in situformed copper nanoparticles. ACS Appl Mater Interfaces. 2017;9(40):35411-35418. doi:10.1021/acsami.7b10541

119. Ranjan S, Ramalingam C. Titanium dioxide nanoparticles induce bacterial membrane rupture by reactive oxygen species generation. Environ Chem Lett. 2016;14(4):487-494. doi:10.1007/ s10311-016-0586-y

120. Huang -Y-Y, Choi H, Kushida Y, Bhayana B, Wang Y, Hamblin MR. Broad-spectrum antimicrobial effects of photocatalysis using titanium dioxide nanoparticles are strongly potentiated by addition of potassium iodide. Antimicrob Agents Chemother. 2016;60 (9):5445-5453. doi:10.1128/AAC.00980-16

121. Venkatasubbu GD, Baskar R, Anusuya T, Seshan CA, Chelliah R. Toxicity mechanism of titanium dioxide and zinc oxide nanoparticles against food pathogens. Colloids Surf B Biointerfaces. 2016;148:600-606. doi:10.1016/j.colsurfb.2016.09.042

122. Chen S, Guo Y, Zhong H, et al. Synergistic antibacterial mechanism and coating application of copper/titanium dioxide nanoparticles. Chem Eng J. 2014;256:238-246. doi:10.1016/j. cej.2014.07.006

123. Brunet L, Lyon DY, Hotze EM, Alvarez PJJ, Wiesner MR. Comparative photoactivity and antibacterial properties of c60 fullerenes and titanium dioxide nanoparticles. Environ Sci Technol. 2009;43(12):4355-4360. doi:10.1021/es803093t

124. Liu N, Chang Y, Feng Y, et al. $\{101\}-\{001\}$ Surface heterojunction-enhanced antibacterial activity of titanium dioxide nanocrystals under sunlight irradiation. ACS Appl Mater Interfaces. 2017;9 (7):5907-5915. doi:10.1021/acsami.6b16373

125. Kalathil S, Khan MM, Ansari SA, Lee J, Cho MH. Band gap narrowing of titanium dioxide ( $\mathrm{TiO} 2$ ) nanocrystals by electrochemically active biofilms and their visible light activity. Nanoscale. 2013;5(14):6323-6326. doi:10.1039/c3nr01280h

126. Ghosal K, Agatemor C, Špitálsky Z, Thomas S, Kny E. Electrospinning tissue engineering and wound dressing scaffolds from polymer-titanium dioxide nanocomposites. Chem Eng $J$. 2019;358:1262-1278. doi:10.1016/j.cej.2018.10.117

127. Wolfrum EJ, Huang J, Blake DM, et al. Photocatalytic oxidation of bacteria, bacterial and fungal spores, and model biofilm components to carbon dioxide on titanium dioxide-coated surfaces. Environ Sci Technol. 2002;36(15):3412-3419. doi:10.1021/ es011423j

128. Dahl M, Liu Y, Yin Y. Composite titanium dioxide nanomaterials. Chem Rev. 2014;114(19):9853-9889. doi:10.1021/ cr400634p

129. Blecher K, Nasir A, Friedman A. The growing role of nanotechnology in combating infectious disease. Virulence. 2011;2 (5):395-401. doi:10.4161/viru.2.5.17035
130. Lellouche J, Friedman A, Lahmi R, Gedanken A, Banin E. Antibiofilm surface functionalization of catheters by magnesium fluoride nanoparticles. Int $J$ Nanomedicine. 2012;7:1175. doi:10.2147/IJN.S30631

131. Stoimenov PK, Klinger RL, Marchin GL, Klabunde KJ. Metal oxide nanoparticles as bactericidal agents. Langmuir. 2002;18 (17):6679-6686. doi:10.1021/la0202374

132. Haggstrom JA, Klabunde KJ, Marchin GL. Biocidal properties of metal oxide nanoparticles and their halogen adducts. Nanoscale. 2010;2(3):399-405. doi:10.1039/B9NR00245F

133. Shedbalkar U, Singh R, Wadhwani S, Gaidhani S, Chopade BA. Microbial synthesis of gold nanoparticles: current status and future prospects. Adv Colloid Interfac Sci. 2014;209:40-48. doi:10.1016/j.cis.2013.12.011

134. Suresh AK, Pelletier DA, Wang W, et al. Biofabrication of discrete spherical gold nanoparticles using the metal-reducing bacterium shewanella oneidensis. Acta Biomater. 2011;7(5):21482152. doi:10.1016/j.actbio.2011.01.023

135. Rai A, Prabhune A, Perry CC. Antibiotic mediated synthesis of gold nanoparticles with potent antimicrobial activity and their application in antimicrobial coatings. J Mater Chem. 2010;20 (32):6789-6798. doi:10.1039/c0jm00817f

136. Feng Y, Chen W, Jia Y, et al. N-Heterocyclic molecule-capped gold nanoparticles as effective antibiotics against multi-drug resistant bacteria. Nanoscale. 2016;8(27):13223-13227. doi:10.1039/C6NR03317B

137. Zhao Y, Jiang X. Multiple strategies to activate gold nanoparticles as antibiotics. Nanoscale. 2013;5(18):8340-8350. doi:10.1039/ c3nr01990j

138. Bagga P, Hussain Siddiqui H, Akhtar J, Mahmood T, Zahera M, Sajid Khan M. Gold nanoparticles conjugated levofloxacin: for improved antibacterial activity over levofloxacin alone. Curr Drug Deliv. 2017;14(8):1114-1119. doi:10.2174/1567201814666170316113432

139. Payne JN, Waghwani HK, Connor MG, et al. Novel synthesis of kanamycin conjugated gold nanoparticles with potent antibacterial activity. Front Microbiol. 2016;7:607. doi:10.3389/ fmicb.2016.00607

140. Cui Y, Zhao Y, Tian Y, Zhang W, Lü X, Jiang X. The molecular mechanism of action of bactericidal gold nanoparticles on escherichia coli. Biomaterials. 2012;33(7):2327-2333. doi:10.1016/j. biomaterials.2011.11.057

141. Gu H, Ho PL, Tong E, Wang L, Xu B. Presenting vancomycin on nanoparticles to enhance antimicrobial activities. Nano Lett. 2003;3(9):1261-1263. doi:10.1021/n1034396z

142. Pornpattananangkul D, Zhang L, Olson S, et al. Bacterial toxintriggered drug release from gold nanoparticle-stabilized liposomes for the treatment of bacterial infection. J Am Chem Soc. 2011;133(11):4132-4139. doi:10.1021/ja111110e

143. Pillai PP, Kowalczyk B, Kandere-Grzybowska K, Borkowska M, Grzybowski BA. Engineering gram selectivity of mixed-charge gold nanoparticles by tuning the balance of surface charges. Angew Chem Int Ed. 2016;55(30):8610-8614. doi:10.1002/ anie. 201602965

144. Hernandez-Delgadillo R, Velasco-Arias D, Diaz D, et al. Zerovalent bismuth nanoparticles inhibit streptococcus mutans growth and formation of biofilm. Int J Nanomedicine. 2012;7:2109.

145. Zhao Y, Zhang Z, Dang H. A simple way to prepare bismuth nanoparticles. Mater Lett. 2004;58(5):790-793. doi:10.1016/j. matlet.2003.07.013

146. Wang F, Tang R, Yu H, Gibbons PC, Buhro WE. Size-and shapecontrolled synthesis of bismuth nanoparticles. Chem Mater. 2008;20(11):3656-3662. doi:10.1021/cm8004425

147. Gao W, Thamphiwatana S, Angsantikul P, Zhang L. Nanoparticle approaches against bacterial infections. Wiley Interdiscip Rev Nanomed Nanobiotechnol. 2014;6(6):532-547. doi:10.1002/ wnan. 1282 
148. Sadiq IM, Chowdhury B, Chandrasekaran N, Mukherjee A. Antimicrobial sensitivity of escherichia coli to alumina nanoparticles. Nanomed Nanotechnol. 2009;5(3):282-286. doi:10.1016/j. nano.2009.01.002

149. Ji H, Sun H, Qu X. Antibacterial applications of graphenebased nanomaterials: recent achievements and challenges. $A d v$ Drug Deliv Rev. 2016;105:176-189. doi:10.1016/j. addr.2016.04.009

150. Xia M-Y, Xie Y, Yu C-H, et al. Graphene-based nanomaterials: the promising active agents for antibiotics-independent antibacterial applications. $J$ Control Release. 2019;307:16-31. doi:10.1016/j.jconrel.2019.06.011

151. Hu W, Peng C, Luo W, et al. Graphene-based antibacterial paper. ACS Nano. 2010;4(7):4317-4323. doi:10.1021/nn101097v

152. Akhavan $\mathrm{O}$, Ghaderi E. Toxicity of graphene and graphene oxide nanowalls against bacteria. ACS Nano. 2010;4(10):5731-5736. doi:10.1021/nn101390x

153. Paszkiewicz S, Szymczyk A. Graphene-based nanomaterials and their polymer nanocomposites. In: Nanomaterials and Polymer Nanocomposites. Elsevier; 2019:pp 177-216.

154. Shaker MA, Shaaban MI. Formulation of carbapenems loaded gold nanoparticles to combat multi-antibiotic bacterial resistance: in vitro antibacterial study. Int $J$ Pharm. 2017;525(1):71-84. doi:10.1016/j.ijpharm.2017.04.019

155. Xu J, Xu B, Shou D, Xia X, Hu Y. Preparation and evaluation of vancomycin-loaded N-trimethyl chitosan nanoparticles. Polymers (Basel). 2015;7(9):1850-1870. doi:10.3390/polym7091488

156. Tom RT, Suryanarayanan V, Reddy PG, Baskaran S, Pradeep T. Ciprofloxacin-protected gold nanoparticles. Langmuir. 2004;20 (5):1909-1914. doi:10.1021/la0358567

157. Friedman AJ, Phan J, Schairer DO, et al. Antimicrobial and antiinflammatory activity of chitosan-alginate nanoparticles: a targeted therapy for cutaneous pathogens. J Invest Dermatol. 2013;133(5):1231-1239. doi:10.1038/jid.2012.399

158. Yoksan R, Chirachanchai S. Silver nanoparticle-loaded chitosanstarch based films: fabrication and evaluation of tensile, barrier and antimicrobial properties. Mater Sci Eng C. 2010;30(6):891897. doi:10.1016/j.msec.2010.04.004

159. Smith AW. Biofilms and antibiotic therapy: is there a role for combating bacterial resistance by the use of novel drug delivery systems? Adv Drug Deliv Rev. 2005;57(10):1539-1550. doi:10.1016/j.addr.2005.04.007

160. Zhao Y, Dai X, Wei X, et al. Near-infrared light-activated thermosensitive liposomes as efficient agents for photothermal and antibiotic synergistic therapy of bacterial biofilm. ACS Appl Mater Interfaces. 2018;10(17):14426-14437. doi:10.1021/ acsami.8b01327

161. Gonzalez Gomez A, Xu C, Hosseinidoust Z. Preserving the efficacy of glycopeptide antibiotics during nanoencapsulation in liposomes. ACS Infect Dis. 2019;5(10):1794-1801. doi:10.1021/ acsinfecdis.9b00232

162. Pushparaj Selvadoss P, Nellore J, Balaraman Ravindrran M, Sekar U. Novel pyochelin-based pegylated liposomes for enhanced delivery of antibiotics against resistant clinical isolates of pseudomonas aeruginosa. Artif Cells Nanomed Biotechnol. 2018;46 (8):2043-2053.

163. Obonyo M, Zhang L, Thamphiwatana S, Pornpattananangkul D, $\mathrm{Fu} \mathrm{V}$, Zhang L. Antibacterial activities of liposomal linolenic acids against antibiotic-resistant helicobacter pylori. Mol Pharm. 2012;9(9):2677-2685. doi:10.1021/mp300243w

164. Yuan Z, Tam VH. Polymyxin B: a new strategy for multidrugresistant gram-negative organisms. Expert Opin Investig Drugs. 2008;17(5):661-668. doi:10.1517/13543784.17.5.661

165. Rukavina Z, Vanić Ž. Current trends in development of liposomes for targeting bacterial biofilms. Pharmaceutics. 2016;8(2):18. doi:10.3390/pharmaceutics 8020018
166. Inoue K. Functional dendrimers, hyperbranched and star polymers. Prog Polym Sci. 2000;25(4):453-571. doi:10.1016/S00796700(00)00011-3

167. Mignani SM, El Brahmi N, El Kazzouli S. Original multivalent gold (III) and dual gold (III)-copper (II) conjugated phosphorus dendrimers as potent antitumoral and antimicrobial agents. $\mathrm{Mol}$ Pharm. 2017;14(11):4087-4097. doi:10.1021/acs.molpharmaceut. $7 \mathrm{~b} 00771$

168. Balogh L, Swanson DR, Tomalia DA, Hagnauer GL, McManus AT. Dendrimer- silver complexes and nanocomposites as antimicrobial agents. Nano Lett. 2001;1(1):18-21. doi:10.1021/ nl005502p

169. Hetrick EM, Shin JH, Paul HS, Schoenfisch MH. Anti-biofilm efficacy of nitric oxide-releasing silica nanoparticles. Biomaterials. 2009;30(14):2782-2789. doi:10.1016/j. biomaterials.2009.01.052

170. Roe D, Karandikar B, Bonn-Savage N, Gibbins B, Roullet J-B. Antimicrobial surface functionalization of plastic catheters by silver nanoparticles. J Antimicrob Chemother. 2008;61(4):869876. doi:10.1093/jac/dkn034

171. Sapsford KE, Algar WR, Berti L, et al. Functionalizing nanoparticles with biological molecules: developing chemistries that facilitate nanotechnology. Chem Rev. 2013;113(3):1904-2074. doi:10.1021/cr300143v

172. Bing W, Chen Z, Sun H, et al. Visible-light-driven enhanced antibacterial and biofilm elimination activity of graphitic carbon nitride by embedded Ag nanoparticles. Nano Res. 2015;8 (5):1648-1658. doi:10.1007/s12274-014-0654-1

173. Guo G, Zhou H, Wang Q, et al. Nano-layered magnesium fluoride reservoirs on biomaterial surfaces strengthen polymorphonuclear leukocyte resistance to bacterial pathogens. Nanoscale. 2017;9 (2):875-892. doi:10.1039/C6NR07729C

174. Geilich BM, Gelfat I, Sridhar S, van de Ven AL, Webster TJ. Superparamagnetic iron oxide-encapsulating polymersome nanocarriers for biofilm eradication. Biomaterials. 2017;119:78-85. doi:10.1016/j.biomaterials.2016.12.011

175. Dinali R, Ebrahiminezhad A, Manley-Harris M, Ghasemi Y, Berenjian A. Iron oxide nanoparticles in modern microbiology and biotechnology. Crit Rev Microbiol. 2017;43(4):493-507. doi:10.1080/1040841X.2016.1267708

176. Anghel I, Grumezescu AM, Andronescu E, et al. Magnetite nanoparticles for functionalized textile dressing to prevent fungal biofilms development. Nanoscale Res Lett. 2012;7(1):501. doi:10.1186/1556-276X-7-501

177. Chifiriuc C, Grumezescu V, Grumezescu AM, Saviuc C, Lazăr V, Andronescu E. Hybrid magnetite nanoparticles/rosmarinus officinalis essential oil nanobiosystem with antibiofilm activity. Nanoscale Res Lett. 2012;7(1):209. doi:10.1186/1556-276X-7209

178. Alavi M, Karimi N. Ultrasound assisted-phytofabricated fe 304 NPS with antioxidant properties and antibacterial effects on growth, biofilm formation, and spreading ability of multidrug resistant bacteria. Artif Cells Nanomed Biotechnol. 2019;47 (1):2405-2423. doi:10.1080/21691401.2019.1624560

179. Kim H, Jones MN. The delivery of benzyl penicillin to staphylococcus aureus biofilms by use of liposomes. $J$ Liposome Res. 2004;14(3-4):123-139. doi:10.1081/LPR200029887

180. Huang C-M, Chen C-H, Pornpattananangkul D, et al. Eradication of drug resistant staphylococcus aureus by liposomal oleic acids. Biomaterials. 2011;32(1):214-221. doi:10.1016/j.biomaterials. 2010.08.076

181. Lee W-H, Loo C-Y, Traini D, Young PM. Nano-and micro-based inhaled drug delivery systems for targeting alveolar macrophages. Expert Opin Drug Deliv. 2015;12(6):1009-1026. doi:10.1517/ 17425247.2015.1039509 
182. Kim B, Pang H-B, Kang J, Park J-H, Ruoslahti E, Sailor MJ. Immunogene therapy with fusogenic nanoparticles modulates macrophage response to staphylococcus aureus. Nat Commun. 2018;9(1):1-13. doi:10.1038/s41467-017-02088-w

183. Wang $\mathrm{L}, \mathrm{Hu} \mathrm{C}$, Shao $\mathrm{L}$. The antimicrobial activity of nanoparticles: present situation and prospects for the future. Int $J$ Nanomedicine. 2017;12:1227. doi:10.2147/IJN.S121956

184. Gao W, Chen Y, Zhang Y, Zhang Q, Zhang L. Nanoparticle-based local antimicrobial drug delivery. Adv Drug Deliv Rev. 2018;127:46-57. doi:10.1016/j.addr.2017.09.015

185. Hindi KM, Ditto AJ, Panzner MJ, et al. The antimicrobial efficacy of sustained release silver-carbene complex-loaded 1-tyrosine polyphosphate nanoparticles: characterization, in vitro and in vivo studies. Biomaterials. 2009;30(22):3771-3779. doi:10.1016/ j.biomaterials.2009.03.044

186. Graves JL, Thomas M, Ewunkem JA. Antimicrobial nanomaterials: why evolution matters. Nanomaterials. 2017;7(10):283. doi:10.3390/nano7100283

187. Ventola CL. Progress in nanomedicine: approved and investigational nanodrugs. Pharm Ther. 2017;42(12):742.

188. Stankic S, Suman S, Haque F, Pure VJ. Multi metal oxide nanoparticles: synthesis, antibacterial and cytotoxic properties. $J$ Nanobiotechnol. 2016;14(1):73. doi:10.1186/s12951-0160225-6
189. da Silva BL, Caetano BL, Chiari-Andréo BG, Pietro RCLR, Chiavacci LA. Increased antibacterial activity of $\mathrm{ZnO}$ nanoparticles: influence of size and surface modification. Colloids Surf B Biointerfaces. 2019;177:440-447. doi:10.1016/j.colsurfb.2019.02. 013

190. Munir MU, Ihsan A, Javed I, et al. Controllably biodegradable hydroxyapatite nanostructures for cefazolin delivery against antibacterial resistance. ACS Omega. 2019;4(4):7524-7532. doi:10.1021/acsomega.9b00541.

191. Zare EN, Makvandi P, Borzacchiello A, Tay FR, Ashtari B, Padil VVT. Antimicrobial gum bio-based nanocomposites and their industrial and biomedical applications. Chem Commun. 2019;55 (99):14871-14885. doi:10.1039/C9CC08207G

192. Singh J, Dhaliwal AS. Synthesis, characterization and swelling behavior of silver nanoparticles containing superabsorbent based on grafted copolymer of polyacrylic acid/guar gum. Vacuum. 2018;157:51-60. doi:10.1016/j.vacuum.2018.08.017

193. Othman SH. Bio-nanocomposite materials for food packaging applications: types of biopolymer and nano-sized filler. Agric Sci Proc. 2014;2:296-303.

194. Zare EN, Lakouraj MM, Mohseni M. Biodegradable polypyrrole/ dextrin conductive nanocomposite: synthesis, characterization, antioxidant and antibacterial activity. Synth Met. 2014;187:9-16.
International Journal of Nanomedicine

\section{Publish your work in this journal}

The International Journal of Nanomedicine is an international, peerreviewed journal focusing on the application of nanotechnology in diagnostics, therapeutics, and drug delivery systems throughout the biomedical field. This journal is indexed on PubMed Central, MedLine, CAS, SciSearch ${ }^{\mathbb{R}}$, Current Contents ${ }^{\mathbb{R}} /$ Clinical Medicine, $^{-}$

\section{Dovepress}

Journal Citation Reports/Science Edition, EMBase, Scopus and the Elsevier Bibliographic databases. The manuscript management system is completely online and includes a very quick and fair peer-review system, which is all easy to use. Visit http://www.dovepress.com/ testimonials.php to read real quotes from published authors. 